\title{
Multiple-Criteria-Based Electric Vehicle Charging Infrastructure Design Problem
}

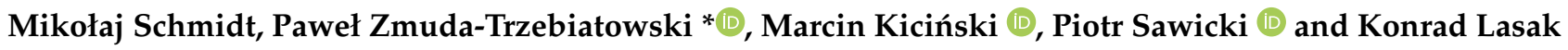 \\ Faculty of Civil and Transport Engineering, Poznan University of Technology, 60-965 Poznań, Poland; \\ mikolaj.schmidt21@gmail.com (M.S.); marcin.kicinski@put.poznan.pl (M.K.); piotr.sawicki@put.poznan.pl (P.S.); \\ konradlasak@mail.com (K.L.) \\ * Correspondence: pawel.zmuda-trzebiatowski@put.poznan.pl; Tel.: +48-61-665-2716
}

Citation: Schmidt, $\mathrm{M}$

Zmuda-Trzebiatowski, P.; Kiciński,

M.; Sawicki, P.; Lasak, K.

Multiple-Criteria-Based Electric Vehicle Charging Infrastructure Design Problem. Energies 2021, 14, 3214. https://doi.org/10.3390/ en14113214

Academic Editor: Hugo Morais

Received: 29 April 2021

Accepted: 28 May 2021

Published: 31 May 2021

Publisher's Note: MDPI stays neutral with regard to jurisdictional claims in published maps and institutional affiliations.

Copyright: (c) 2021 by the authors. Licensee MDPI, Basel, Switzerland. This article is an open access article distributed under the terms and conditions of the Creative Commons Attribution (CC BY) license (https:/ / creativecommons.org/licenses/by/ $4.0 /)$.
Abstract: The article presents the issue of designing a network of electric vehicle charging stations (EVCSs) for servicing passenger and commercial vehicles and taking into account the already existing locations. The authors propose a five-stage multicriteria- and GIS-based EVCS location methodology (5MAGISEV) for designing the EVCS network that includes defining potential EVCS locations (stage 1), constructing a family of evaluation criteria (stage 2), generating alternatives (stage 3), selecting an appropriate multiple criteria decision aid method (stage 4) and conducting a multicriteria evaluation of alternatives (stage 5). The methodology was verified by its experimental application for solving the problem of EVCS location in Poznan, Poland. As a result of its application, a set of over 155,000 alternatives was generated in view of different EVCS location determination policies. A family of eight criteria with subcriteria was proposed to assess the solutions, including the evaluation of the degree of integration of the considered EVCSs with such issues as public transport (C1); urbanized areas (C2); main road network (C3); industrial areas (C4); and the location with respect to transport areas (C5), shops of various types (C6), address points (C7) and DYI stores (C8). Based on the selected method of multiple criteria decision aid (LBS), a solution was selected that constitutes a compromise design of the EVCS network.

Keywords: location problem; electromobility; electric vehicle charging station (EVCS); 5MAGISEV; multiple criteria decision aid (MCDA); light beam search (LBS) method

\section{Introduction}

\subsection{Electromobility and Its Key Decision Problems}

Changing the propulsion of cars from fossil fuels to electricity is seen as one way of reducing $\mathrm{CO}_{2}$ emissions globally. The expected benefits are increasing as the technology develops and the share of fossil fuels in the energy mix decreases (e.g., [1,2]). It is estimated that the number of electric vehicle (EV) models available on the European market will exceed 200 in 2021, while the annual manufacturing of these cars will reach around 4 million vehicles in 2025. As a result of the increasing number of EVs, their number per one public charging point in Europe increased from 5 to 7 between 2017 and 2019 [3]. Besides the strategy of tax reductions or exemptions related to the purchase of vehicles, one of the perceived barriers to the development of electromobility [4] is the inadequate network of electric vehicle charging stations (EVCSs) [5-7], both in cities and rural areas. The fear people have about the limited range of electric vehicles is not insignificant for electromobility [8]. Therefore, implementing policies that support electromobility development is seriously considered (see [9-11]). In Poland, the Act on Electromobility and Alternative Fuels has imposed an obligation on larger cities to provide a certain minimum number of publicly accessible electric vehicle charging points (EVCPs) by the end of 2020. An EVCP is understood as one independent parking space with an accompanying charger that can be used by one vehicle at a time. One EVCS can provide mulitple EVCPs. Electric vehicle charging infrastructure (EVCI) is not very extensive in Poland. At the beginning of 2021, 
approximately 1450 publicly accessible EVCPs were registered in the official Register of Alternative Fuels Infrastructure (EIPA) in Poland. In the city of Poznan considered in this study, this number was lower than that required by the Act.

\subsection{State of the Art in EVCS Location}

In recent years, there has been a growing interest in two mutually interacting topics related to EVCI, i.e., (1) the location of EVCSs or the design of their network [12-21] (supply perspective) and (2) the modeling of EV usage (demand perspective), which includes planning their routes and strategies of vehicle charging [18,22-35]. One of the problems related to the modeling of EV usage is the relative scarcity of real-world data, especially when compared to cars powered by internal combustion engines (ICEs). There is also some uncertainty about the suitability of using methods developed primarily for ICE cars in e-car usage modeling. However recent research by Pareschi et al. [31] suggests that household travel surveys are an appropriate instrument for describing the mobility behavior of EVs. From the point of view of infrastructure, it should be noted that the EVCSs interact with each other, so evaluating any location depends on the locations of the other points in the network. For this reason, the formulation of the problem of the location of electric vehicle charging points may be reduced to the selection of the most desirable variant of the network [14].

Pagany et al. [13], reviewing more than 660 scientific papers published between 1986 and 2016, noted that it had only been since 2009 that the number of studies in the field in question began to increase significantly. Based on a detailed analysis of 119 articles, the authors gathered information on the criteria used to assess charging points' location. In addition to the usual criteria related to the cost of building the infrastructure, user perspective criteria such as travel demand, travel time or distance of the charging point from the origin and destination, as well as route perspective criteria such as trip length, traffic congestion and queuing were identified. In the work of Pagany et al. [13], the input data for the models included statistical data from censuses and travel data for electric or conventionally powered cars.

Minimizing the number of points that allow meeting the estimated demand was also the optimization criterion in several subsequent deliberations [36-38]. In the study by Bouguerry and Layeba [36], determining the location of charging points was combined with the problem of determining their number within a given location. The distance required to walk between the charging point and the workplace was also an additional optimization criterion. This criterion was also found in the work of Gong et al. [39]. While in some studies, the distance covered on foot was a limitation and amounted to a maximum of $250 \mathrm{~m}$ (Guler and Yomralioglu [40]), in others, it was $500 \mathrm{~m}$ (Bian et al. [41]). However, in the paper by Efthymiou et al. [37], a genetic algorithm approach was used to solve the optimization problem and an origin-destination matrix of conventionally fueled vehicle trips. It is noteworthy that while some relevance can be seen in the information on transport demand or supply (for both ICE and electric cars) available in transport models, these models may not be available in practice in every city, and they may be quite expensive to prepare. In some of the studies, the evaluation criteria are related to the interests of the actors involved in the charging process. From the perspective of public EVCS network operators, it is important to consider not only the investment costs but also the profitability of operating a station at a given point $[11,42]$. The location of charging points in public places (public hotspots) can represent an additional source of revenue for the owners and managers of these venues [43-45], yet on the other hand, the costs resulting from excessive or inadequate utilization of such hotspots need to be considered [46,47].

According to Wang et al. [48], for determining urban demand, groups of individual, single-shift and double-shift e-taxi users were defined, and two categories of charging points-normal and high-power-were identified for supply locations. In addition to e-taxis, attention can also be given to electric light commercial vehicle (e-LCV) users, who can also potentially benefit from publicly available EVCIs. Figenbaum [49] indicated that 
the entrepreneurs surveyed were reluctant to ask their customers to use the chargers. Hence, it may be reasonable to locate public EVCIs near other places where they may spend more time, such as DIY stores. However, it is worth noting that some users may have difficulty using public EVCSs in their working time due to their work nature. For example, couriers make a large number of short stops during the day [50]. In such cases, charging can only occur outside working hours, possibly while in a distribution center or at pick-up-drop-off points. However, chargers at these locations may not necessarily belong to the EVCI public network.

Jochem et al. [38], Kong et al. [51] and Liu et al. [14] related their considerations to journeys made over longer distances-motorway journeys-for which drivers may be concerned about battery depletion, and they also drew attention to queuing times and the speed of the charging process itself. For example, Jochem et al. [38] used a flow-refueling location model, which minimizes the required number of fast-charging stations (FCSs) for a given road network. The model was used to estimate the required number of FCSs along the selected European Union countries' motorways. In turn, Liu et al. [14] presented three location solutions taking into account the following criteria: minimizing social cost, minimizing charging station operation and minimizing charging station construction, in which they took into account the identified expectations of drivers. These costs were then aggregated to a total cost and were subject to optimization.

When considering charging station efficiency and location, it is also worth considering the preferences of plug-in hybrid (PHEV) and EV users. Arslan and Karasan [52] drew attention to the possibility of using two energy sources in PHEV cars. From the user's perspective, this opportunity translates into a continuous cost analysis between electricity and gasoline and a more extended range compared to electric vehicles. As a result, the authors proposed a solution to the charging station location problem for the California state road network where the distance traveled by vehicles on electricity is maximized, which translates into the cost of PHEV travel. Another study suggests that early adopters of PHEVs and EVs prefer to charge at home [10] or both at home and work [11]. Charging in public places such as shops, while rarely used, is nevertheless essential for the attractiveness of e-mobility. It should be noted that, in addition to shops, other trip destinations can be identified as requiring a prolonged stay that might allow EV charging. The issues of time needed to charge the vehicle are sometimes (see [53]) taken into account when considering the location of urban charging stations, a topic which is addressed in this paper. Locating EVCSs near points of interest (POIs) where the average EV or PHEV user spends less time, such as petrol stations, may not be desirable when planning an urban public EVCI network.

Notably, the nature of urban travel differs from intercity travel, which may be reflected in the issue of EVCI location. This was highlighted by Csiszár [54] in an approach that combines a macroscale model with a microscale one. When solving the problem in cities at the microscale, the use of information on parking availability was proposed. This approach was developed with other criteria in the study by Csiszár et al. [55]. On a macroscale, local and tourist traffic is considered, while on a microscale, commercial and service facilities (post office, bank, administration), public transport stops, park and ride car parks, petrol stations and tourist and commercial facilities are included. Pagany et al. [56] proposed a microscale model in which they determined the level of demand for electric car charging service for potential public or quasipublic POIs. This need was determined based on such parameters as average time and frequency of users' visits at a given POI.

The proposals for solving the problem of electric vehicle charging stations' location take into account several criteria, which means that the issue should be approached holistically. Apart from the economic [14,24,42,57-67], environmental [40,61,65,68-70] and technical criteria $[14,46,51,58,60,61,65,71-73]$, there are also the social criteria that need to be considered [39-41,60,61,72,74,75]. Additionally, besides the single criterion proposals $[24,41,46,57,74,76-78]$ there are currently more and more multi-criteria approaches [40, 43,56,58,60,61,64,65,70,72,79-81]. The methodology proposed by Erbaş [70] for the evaluation of EVCS location in Ankara may serve here as an example. The family of 15 criteria is 
divided into three categories: environmental/geographical (distance to vegetation, water resources or landslide risk; the slope of the land, the possibility of expansion, the risk of an earthquake), economic (land cost, EV ownership in the service area and distance to power cut) and urban (service area population; proximity to junctions, main roads, the substation, a petrol station and other electric vehicle charging stations). As can be seen, some of the criteria identified above are local, suggesting that the sets of criteria can be adapted to the nature of a particular city, agglomeration or country. Guler and Yomralioglu included ten criteria in their multicriteria approach for locating charging stations in three districts of Istanbul (Atasehir, Uskudar and Kadikoy) [40]. Both approaches integrate the geographic information system (GIS) techniques and multicriteria decision making (MCDM) (in these cases, fuzzy AHP and TOPSIS methods). However, these papers focus on analyzing the attractiveness of areas for EVCS locations while failing to analyze their interactions within the network or the use of predefined locations such as car parks.

In the case of the city of Poznan considered in this study, a multicriteria approach based on GIS and other data was presented in the paper by Szymańska et al. [58]. In this paper, a preliminary assessment of the possibility of solving the problem of EVCS location was made using a number of evaluation criteria, including the cost of construction, the share of high-power charging points, the availability of charging points, the coverage of densely populated and commercially developed areas with charging points and the integration with public transport. Four variants differing in the number of stations were analyzed. Machelski and Grzeczka [82], on the other hand, applied a multicriteria approach to a similar problem of grouping the existing EVCS sites into homogeneous packages in terms of attractiveness for tenders to select charging station operators, using the Electre III method.

The register of key papers dealing with EVCS location and EVCI construction is presented in Table A1 (Appendix A). The table consolidates the knowledge on the applied evaluation criteria, methodological aspects and considered types of the target group of vehicles. To summarize the state of knowledge in this respect, it should be stated that the authors focus on the construction of solutions dedicated both to electric passenger vehicles (EVs) and light commercial electric vehicles (e-LCVs), considering each of these types separately. In a significant number of cases, the problem of charging stations' location is connected with determining their number, taking into account the intensity and motivation of journeys and the technical parameters connected with the process of battery charging. The trips that constitute the basis for determining the need for EVCSs involve both conventionally and electrically powered vehicles. The selection of EVCS location points is made from a set of public or private locations, depending on the nature of the tasks performed and the type of vehicle fleet under consideration. When considering the criteria for evaluation of the solutions, it is noticeable that practically all categories of criteria are used, from economic to technical, environmental and social ones. From a methodological point of view, the authors of the published studies use either a single-criterion- or multicriteria-based location selection optimization approach. In the first case, a mathematical model from the category of location problems is constructed, based mainly on mixed-integer linear programming, or another mathematical programming task is combined with a GIS class system with the aim of finding an optimal EVCS network design. In the multicriteria approach, potential locations of EVCSs are independently evaluated by applying multiple criteria decision-aid tools.

Based on the literature review in the field of solving the problem of EVCS location, the authors of this paper have identified a research gap. It involves the lack of a complex methodology for selecting EVCS locations in urban areas, which at the same time could combine the demand for passenger cars and e-LCVs. The complexity of the methodology should be considered in three dimensions. First, it should take into account a wide spectrum of criteria applied for evaluating the competing locations (the use of MCDA is expected), as well as land-use and other constraints that may prevent the construction of an EVCS at a potential location. The land-use constraints are especially important in urban contexts. Secondly, the interaction between EVCS locations and other types of infrastructure 
should be included (the combination of GIS and network analysis is expected). Finally, the methodology should allow for taking into account the existing EVCS locations.

\subsection{Objective of the Paper}

Based on the literature review results, the authors propose a methodology for designing a network of EVCSs for the urban agglomerations, called "five-stage multicriteria- and GIS-based electric vehicle charging station location methodology" (5MAGISEV). In this approach, a large set of alternative solutions, i.e., different locations of a finite number of EVCSs, are generated, and the number of EVCSs in the alternative is fixed. The process of generation of alternatives accounts for the already existing EVCSs at the considered territory. It also involves the interaction between every single EVCS in the designed network thanks to integrating geographic information system (GIS) within the decision problem. Generation of efficient alternatives is iterative, and it is alternatively focused on different policies for locating EVCSs in the considered territory, including locating EVCSs in a selected type or several types of points or balancing the deployment. The selection of the final solution results from the decision-aiding process, where a compromise is reached based on the set of evaluation criteria according to the decision-maker's preferences. The proposed methodology has also been experimentally verified by its exemplary application to the Poznan, Poland, agglomeration as a definition of target EVCI with respect to the existing EVCSs. In other words, the approach proposed in this paper combines key separate methodological approaches discussed in Section 1.2 and applies them together to solve the EVCS network design problem with the use of MCDA.

\section{Methodology of Defining Electric Vehicle Charging Infrastructure}

\subsection{Key Assumptions}

With reference to the objective of the article, as defined in Section 1.3, several assumptions were made. First, the methodology for defining an EVCI takes into account all already existing public EVCSs. Second, the EVCS location is established on the premises of the existing car park, located in the vicinity of facilities, i.e., buildings with specific utility functions. Third, while selecting new locations for EVCSs in the planned network, petrol stations are not taken into account. Instead, places where electric vehicle users spend a significant amount of time, such as shops, home and work, are of high priority. Fourth, the expected network should enable charging both passenger and light commercial electric vehicles (e-LCVs). Fifth, the number of EVCSs that constitute the alternative EVCI is constant due to the formal regulations.

\subsection{The General Concept of Methodology}

The 5MAGISEV methodology is composed of five key stages: Stage 1, defining potential locations of EVCSs; Stage 2, construction of the family of evaluation criteria; Stage 3, generation of alternatives; Stage 4, selection of the multiple criteria decision aiding method; and Stage 5, multiple criteria evaluation of alternatives. The final result of such a methodology is a suggested electric vehicle charging infrastructure in the considered territory defined as a compromise accounting for all of the criteria.

All of the stages are related to each other, according to the model described in Figure 1. 


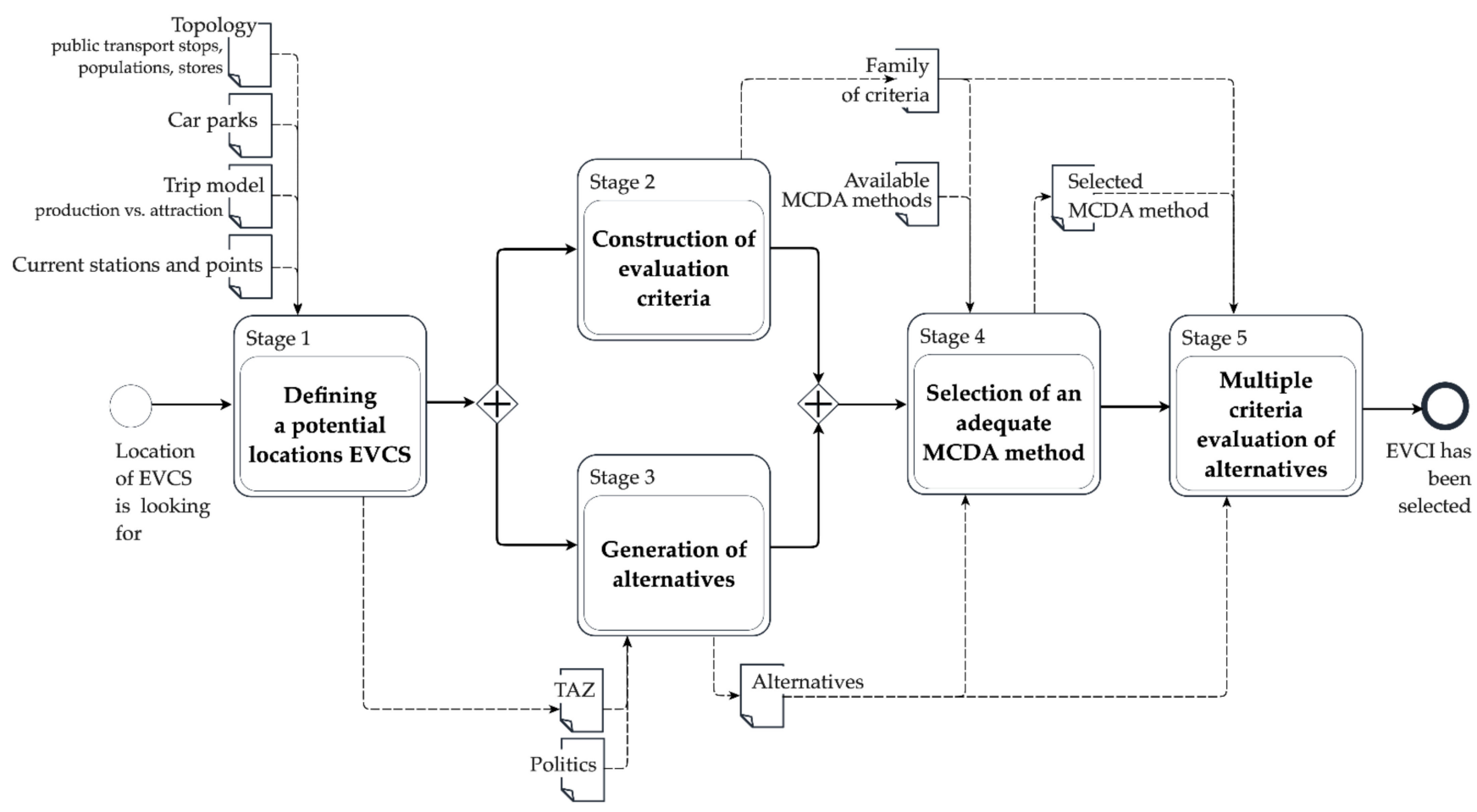

Figure 1. The concept of the proposed methodology of EVCI design.

\subsection{Key Steps of the Methodology}

\subsubsection{Notation}

All the indexes, parameters and variables used in the methodology are presented in Tables 1 and 2.

Table 1. This list of indexes in alphabetical order.

\begin{tabular}{cc}
\hline Symbol & Definition \\
\hline$i$ & Potential location of ECVS, $i=1,2, \ldots, I$ \\
$j$ & A traffic analysis zone (TAZ), \\
& $j=1,2, \ldots, \beta, \beta+1, \beta+2, \ldots, \gamma, \gamma+1, \gamma+2, \ldots, J$ \\
$k$ & An alternative, i.e., a location of EVCSs as a part of ECVI on a considered \\
$l$ & territory, $k=1,2, \ldots, K$ \\
$n$ & An address location, $l=1,2, \ldots, L$ \\
$r$ & A location of store (all types) $, n=1,2, \ldots, N$ \\
$s$ & A public transport stop location, $p=1,2, \ldots, P$ \\
$u$ & An urban zone, $r=1,2, \ldots, R$ \\
$v$ & An arc of main road system, $s=1,2, \ldots, S$ \\
& An industrial zone, $u=1,2, \ldots, U$ \\
& A location of DIY store, $v=1,2, \ldots, V$ \\
\hline
\end{tabular}


Table 2. This list of parameters and decision variables in alphabetical order.

\begin{tabular}{|c|c|}
\hline Symbol & Definition \\
\hline$A_{j}$ & Area size of $j$ traffic analysis zone (TAZ), $j=1,2, \ldots, J$ \\
\hline$A_{l}$ & An area of $l$ addresses \\
\hline$B_{i}$ & A zone around $i$ potential EVCS location with nonzero radius \\
\hline$B_{i}(l)$ & A zone around $i$ potential EVCS location of radius $l$ \\
\hline$B_{i}\left(l^{h p}\right)$ & $\begin{array}{c}\text { A zone around } i \text { potential EVCS location of radius } l^{h p} \text {, i.e., a higher preferred } \\
\text { distance to EVCS, } l^{h p}<l^{l p}\end{array}$ \\
\hline$B_{i}\left(l^{l p}\right)$ & $\begin{array}{c}\text { A zone around } i \text { potential EVCS location of radius } l^{l p} \text {, i.e., a less preferred } \\
\text { distance to EVCS, } l^{h p}<l^{l p}\end{array}$ \\
\hline$l_{i u}$ & A distance between centroid of $u$ industrial zone and $i$ potential EVCS location \\
\hline$H_{r}$ & A set of $r$ urban zones \\
\hline$N$ & A finite number of EVCSs in the alternative solution \\
\hline$S_{p}^{I}$ & A set of $p$ stops that belongs to a primary public transport system \\
\hline$S_{p}^{I I}$ & A set of $p$ stops that belongs to a secondary public transport system \\
\hline$P_{r}$ & A population of $r$ urban zone \\
\hline$R_{S}$ & A set of arcs of the main road system \\
\hline$W_{n}$ & A set of $n$ stores \\
\hline$W_{v}$ & A set of $v$ DIY stores \\
\hline$W_{u}^{c}$ & A set of $u$ industrial areas, with defined centroids \\
\hline$x_{i}$ & $\begin{array}{l}\text { A binary variable to accept or reject the location of EVCS in the } i \text { location, } \\
\qquad i=1,2, \ldots, I\end{array}$ \\
\hline$y_{i}^{f i x}$ & $\begin{array}{c}\text { A location of existing EVCS at the considered territory; its location is previously } \\
\text { determined and fixed }\end{array}$ \\
\hline \multirow[t]{2}{*}{$Z_{j}$} & $\begin{array}{c}\text { A set of traffic analysis zones (TAZ), } j=1,2, \ldots, J \text { divided into subsets of TAZ, } \\
\text { where } Z_{J}=Z_{j}^{A} \cap Z_{j}^{B} \cap Z_{j}^{C} \text {, and }\end{array}$ \\
\hline & $Z_{j}^{A}: j=1,2, \ldots, \beta ; Z_{j}^{B}: j=\beta+1, \beta+2, \ldots, \gamma, Z_{j}^{C}: j=\gamma+1, \gamma+2, \ldots, J$ \\
\hline
\end{tabular}

\subsubsection{Stage 1-Defining the Potential Location of EVCSs}

It is assumed that the design of EVCI is composed of a finite number of EVCSs located at the existing car parks. These car parks should be publicly available to make sure that the generated EVCI is a feasible solution. The car parks selected as potential EVCS locations should also provide sufficient space. It should be greater than the assumed number of EVCPs to be installed. As suggested by Bonges and Lusk [83], this is to facilitate the installation of EVCSs in places where one can start charging a vehicle without removing the previous one. This capacity should also be sufficient so that after using several parking spaces on the EVCP, it would still be possible to park cars with conventional engines unless city policy deliberately excludes this possibility. In case there are too many potential locations, cluster analysis tools, e.g., dbscan, can be used. This should allow, for example, to treat parking spaces located on both sides of the street as one facility.

In the proposed methodology, every potential EVCS location is indexed by $i$, where $i=1,2, \ldots, I$. Due to the possible location of EVCSs in the specific part of the considered territory, a domain of index $i$ is divided into subsets to exact potential locations in the following subterritories:

- "Clean transport zones": $i=1,2, \ldots, \lambda$;

- Next to the shopping centers: $i=\lambda+1, \lambda+2, \ldots, \mu$;

- $\quad$ Next to the supermarkets: $i=\mu+1, \mu+2, \ldots, \xi$;

- At the other locations: $i=\xi+1, \xi+2, \ldots, I$.

Formally, the potential locations of EVCSs are described by $i=1,2, \ldots, \lambda, \lambda+1$, $\lambda+2, \ldots, \mu, \mu+1, \mu+2, \ldots, \xi, \xi+1, \xi+2, \ldots, I$. Dividing car parks into groups allows prioritizing different types of areas and POIs by specifying how many potential locations from each group should be included in the alternatives generated during Stage 3 of the methodology. The location of EVCSs in clean transport zones supports the city's policy of promoting e-mobility. These are also the locations that favor the use of e-cars. The choice of shopping centers and supermarkets as relevant POIs is based on the fact that 
shopping can take sufficient time to make charging the vehicle possible. These entities may also be interested in locating publicly accessible EVCSs to increase the attractiveness of their facilities. Car parks assigned to these groups should be located in or adjacent to the designated areas/POIs, i.e., within a comfortable walking distance.

The remaining locations have been assigned to the group defined as "other locations" without distinguishing between nearby POIs or areas. However, it should be noted that this approach does not exclude the possibility to list in the policies other types of car park groups, such as P\&R car parks; car parks located in residential areas; or car parks in the vicinity of cinemas, theatres, hospitals or universities.

In addition, the authors did not specify offices, industrial locations and hotels as a separate group as the car parks located at these facilities may not be open to the public.

It is important to note that the created car park groups are hierarchical. One parking area may be located next to several different POIs or within a clean transport zone. In this case, the final assignment to the group is determined by its relative importance. For example, most shopping centers contain a supermarket. However, car parks located next to shopping centers will only be assigned to this group. This approach makes it easier to generate equally numerous alternatives (see Section 2.3.4). In addition, potential car park locations should be grouped according to the level of traffic of each traffic analysis zone (TAZ) in the city. It was proposed to divide TAZs into three mobility groups: high (A), medium (B) and low (C). Combined with the four groups of car parks, a total of 12 classes of potential locations are obtained. Due to the limitations of the transportation model that was available for the city considered in the case study, the level of traffic within each TAZ was measured as the sum of the traffic generated and attracted by that TAZ for all groups of vehicles of any propulsion type. However, when better traffic models are available, the model can be limited to electric and hybrid cars.

\subsubsection{Stage 2-Construction of Evaluation Criteria}

In the considered decision problem, a set of locations of EVCSs is controlled by a binary decision variable $x_{i}$ defined as (1):

$$
x_{i}=\left\{\begin{array}{lll}
1 & \text { if } & \text { EVCS is located in } i-\text { th alternative location } \\
0 & \text { if } & \text { otherwise }
\end{array}\right.
$$

The set of EVCS locations is generated within $k$ iterations, according to the considered policy. Each generated set is next evaluated with respect to the family of eight main criteria $\mathbb{C}=\{C 1, C 2, \ldots, C 8\}$. Criterion $C 1$ evaluates the level of integration of EVCSs with the public transport network. The criterion focuses on the assessment of the availability of a public transport system near EVCSs, which is essential when the EV user/driver wants to continue the journey by public transport. Due to the different roles of the different modes of public transport systems, this criterion can evaluate the integration of core (primary) and comprehensive (secondary) transport networks. Thus, it is suggested to formulate two comprehensive subcriteria, namely C1.1 and C1.2, as the intensity of integration of primary and secondary transport networks with a considered EVCI. The value of the criterion, in any case, expresses the number of stops of the public transport system located at a distance no further than the assumed threshold. Both subcriteria are expressed in units and are maximized; see Formulae (2) and (3).

$$
\begin{aligned}
\mathrm{C} 1.1_{k} & =\max \left(\sum_{i=1}^{I} \sum_{p=1}^{P} x_{i} \cdot\left(B_{i}(l) \cap S_{p}^{I}\right)\right), \\
\mathrm{C} 1.2_{k} & =\max \left(\sum_{i=1}^{I} \sum_{p=1}^{P} x_{i} \cdot\left(B_{i}(l) \cap S_{p}^{I I}\right)\right) .
\end{aligned}
$$


Criterion $\mathrm{C} 2$ defines the population at the productive age that lives in $r$ zones near the $i$-th potential locations of EVCSs and not further than a threshold distance. To express a preference in EVCS location, this criterion is divided into two subcriteria differing in terms of the maximum preferred distance, i.e., highly $\left(l^{h p}\right.$; see C2.1) and less preferred ( $l^{l p}$; see C2.2) distances to $i$ location of EVCS, respectively. This criterion is expressed in persons and is maximized; see Formulae (4) and (5).

$$
\begin{aligned}
& \mathrm{C} 2.1_{k}=\max \left(\sum_{i=1}^{I} \sum_{r=1}^{R} x_{i} \cdot\left(B_{i}\left(l^{h p}\right) \cap H_{r}\right) \cdot P_{r}\right), \\
& \mathrm{C} 2.2_{k}=\max \left(\sum_{i=1}^{I} \sum_{r=1}^{R} x_{i} \cdot\left(B_{i}\left(l^{l p}\right) \cap H_{r}\right) \cdot P_{r}\right) .
\end{aligned}
$$

Criterion C3 evaluates the integration of EVCSs with the city's main road system. It expresses the number of EVCSs located no further than a threshold distance to the city's main roads. To express the location preferences, the EVCS criterion is divided into two subcriteria differing in terms of the maximum preferred distance, i.e., highly ( $l^{h p}$; see C3.1) and less preferred distances $\left(l^{l p} ; C 3.2\right)$ to $i$ location of EVCS, respectively. It is expressed in units and is maximized (see Formulae (6) and (7)).

$$
\begin{aligned}
& \mathrm{C} 3.1_{k}=\max \left(\sum_{i=1}^{I} \sum_{s=1}^{S} x_{i} \cdot\left(B_{i}\left(l^{h p}\right) \cap R_{s}\right)\right), \\
& \mathrm{C} 3.2_{k}=\max \left(\sum_{i=1}^{I} \sum_{s=1}^{S} x_{i} \cdot\left(B_{i}\left(l^{l p}\right) \cap R_{s}\right)\right) .
\end{aligned}
$$

Criterion C4 evaluates an integration of EVCSs with industrial areas, which is an important issue in the e-LCV perspective. The criterion is expressed as a mean distance $l_{i u}$ from the centroids of $u$-th industrial areas to the nearest $i$-th EVCS. It is expressed in meters and is minimized.

$$
C 4_{k}=\min \left(\frac{1}{U} \sum_{i=1}^{I} \sum_{u=1}^{U} x_{i} \cdot\left(B_{i} \cap W_{u}^{\mathrm{c}}\right) \cdot \min \left(l_{i u}\right)\right) .
$$

Criterion C5 determines the availability of an EVCS to the defined traffic analysis zones (TAZs). The share of the summed area of the TAZs with the availability of an EVCS at a distance no further than the threshold value in relation to the total area of the TAZs is determined. Due to the extraction of three types of TAZs, criterion C5 is divided into three subcriteria, namely C5.1, C5.2 and C5.3, each representing a TAZ class (see Equations (9)-(11)). The criterion is expressed in percentage and is maximized.

$$
\begin{gathered}
\mathrm{C} 5.1_{k}=\max \left(100 \cdot \sum_{i=1}^{I} \sum_{j=1}^{\beta} x_{i} \cdot\left(B_{i}(l) \cap Z_{j}^{A}\right) \cdot A_{j} / \sum_{j=1}^{\beta} A_{j}\right), \\
\mathrm{C} 5.2_{k}=\max \left(100 \cdot \sum_{i=1}^{I} \sum_{j=\beta+1}^{\gamma} x_{i} \cdot\left(B_{i}(l) \cap Z_{j}^{B}\right) \cdot A_{j} / \sum_{j=\beta+1}^{\gamma} A_{j}\right), \\
\text { C5.3 } 3_{k}=\max \left(100 \cdot \sum_{i=1}^{I} \sum_{j=\gamma+1}^{J} x_{i} \cdot\left(B_{i}(l) \cap Z_{j}^{C}\right) \cdot A_{j} / \sum_{j=\gamma+1}^{J} A_{j}\right) .
\end{gathered}
$$


Criterion C6 evaluates the share of all types of stores with direct access to an EVCS. The criterion is determined as a share of $n$ stores with access to $i$-th EVCS located no further than a threshold distance to the stores. C6 is dimensionless and is maximized (see Formula (12)).

$$
\mathrm{C}_{k}=\max \left(\frac{1}{N} \sum_{i=1}^{I} \sum_{n=1}^{N} x_{i} \cdot\left(B_{i}(l) \cap W_{n}\right)\right) .
$$

Criterion C7 describes the integration of EVCI with address points at the considered area. The criterion is expressed as a share of the address points located no further than a threshold distance to $i$-th EVCS. It is dimensionless and is maximized (see Formula (13)).

$$
\mathrm{C}_{k}=\max \left(\frac{1}{L} \sum_{i=1}^{I} \sum_{l=1}^{L} x_{i} \cdot\left(B_{i}(l) \cap A_{l}\right)\right) .
$$

Criterion C8 evaluates the share of DYI stores with direct access to the $i$-th EVCS. In this case, contrary to C6, greater weight and size of loads, and thus the more significant popularity of using shopping carts to deliver goods from the store to the vehicle or even pick up goods from the back of the store, are considered. C8 is determined as a percentage of DYI stores with access to EVCSs located no further than a threshold distance to the stores. The criterion is dimensionless and is maximized; see Formula (14).

$$
\mathrm{C}_{k}=\max \left(\frac{1}{V} \sum_{i=1}^{I} \sum_{v=1}^{V} x_{i} \cdot\left(B_{i}(l) \cap W_{v}\right)\right) .
$$

The threshold distance applied to criteria $\mathrm{C} 1$ and $\mathrm{C} 2$ and $\mathrm{C} 5-\mathrm{C} 8$ is related to the walking distances. In the literature (see, e.g., [56,84-86]), such a distance varies from one hundred to several hundred meters, depending on the purpose of the trip and the assumed level of travel comfort. In C3, the threshold distance is related to the extent of the potential journey and the potential ease of finding the points for people less familiar with the topography of the city. Hence, these values should not be large either. It should also be noted that the excessive EVCS location density may adversely affect the obtained result (performance) of the most criteria, i.e., C1, C2 and C5-C8. In that case, the simultaneous access of one point or area to a greater number of EVCSs within the assumed threshold distance does not result in the improvement of the values of these criteria. The opposite is criterion $\mathrm{C} 3$. In the case of criterion $\mathrm{C} 4$, the obtained value depends on the mutual location of industrial areas and the EVCI network. A single EVCS, depending on the location of the others, may be the closest to zero, one or more than one industrial areas.

The family of criteria $\mathbb{C}=\{C 1, C 2, \ldots, C 8\}$ defined at this stage of methodology is composed of eight issues referred to as the EVCI design problem. Several criteria, namely C4, C7 and C8, have been constructed with respect to the design of EVCI and oriented to the e-LCV users, while the remaining criteria, namely C1-C3, C5 and C6, are applicable to both passenger EV and e-LCV users. The set of criteria $\mathbb{C}$ does not include cost-oriented aspects. This is the result of a primary assumption of the constant number of EVCSs generated in each alternative. Consequently, the cost of investment and its maintenance is also the same or on a very similar level, and any differentiation among the alternatives cannot be obtained. However, such a criterion may be added when considering the variants of the EVCI network that make up different numbers of EVCSs.

The set of feasible alternatives is described by 10 constraints. There are nonempty sets of objects to define all criteria, including set of stops of primary (15) and secondary (16) public transport systems, urban zones (17), arcs of the main road system (18), general stores (19), DIY stores (20), industrial areas (21) and traffic analysis zones (22). There is also a sufficient, i.e., greater than expected, number of potential EVCS locations (23). Finally, the number of EVCS locations in each of the alternatives is limited and is $N(24)$. 


$$
\begin{gathered}
\exists S_{p}^{I} \forall p\left(p \in S_{p}^{I}\right) \\
\exists S_{p}^{I I} \forall p\left(p \in S_{p}^{I I}\right) \\
\exists H_{r} \forall r\left(r \in H_{r}\right) \\
\exists R_{s} \forall s\left(s \in R_{s}\right) \\
\exists W_{n} \forall n\left(n \in W_{n}\right) \\
\exists W_{v} \forall v\left(v \in W_{v}\right) \\
\exists W_{u}^{\mathrm{c}} \forall u\left(u \in W_{u}^{\mathrm{c}}\right) \\
\exists Z_{j} \forall j\left(j \in Z_{j}\right) \Rightarrow \exists Z_{j}^{A} \forall j\left(j \in Z_{j}^{A}\right) \wedge \exists Z_{j}^{B} \forall j\left(j \in Z_{j}^{B}\right) \wedge \exists Z_{j}^{C} \forall j\left(j \in Z_{j}^{C}\right) \\
\sum_{i=1}^{I} x_{i} \gg N \\
\sum_{i=1}^{I}\left(x_{i}-y_{i}^{f i x}\right)=N
\end{gathered}
$$

\subsubsection{Stage 3-Generation of Alternatives}

At this stage, a set of alternative criteria $\mathrm{A}=\left\{A_{k}: k=1,2, \ldots, K\right\}$, being a particular configuration of EVCSs at the considered area, is generated according to one or more policies. Each of the policies differs in the number of $i$ locations allocated to each parking group and TAZ listed during Stage 1. Alternatives are obtained by randomizing these locations from all available potential locations in a given parking group. Policies may reflect the concept of fairness preferred by public decision-makers (e.g., in terms of EVCS distribution between city districts) or vision of development in the case of commercial enterprises and current or negotiated agreements with other entities. The considered set may also include additional policies, such as those proposed during consultations by stakeholders or developed by experts. In the latter case, the policies may enable the decision-maker to understand the effects of different assumptions better.

As examples of the applied policies, the following scheme is proposed, in which the randomly selected locations are:

- Uniformly assigned to all groups of car parks, while the allocation of the number of locations to TAZ within each group of car parks is uniformly distributed;

- Uniformly assigned to all groups of car parks, while the allocation of the number of locations to TAZ within each group of car parks varies;

- Differentially allocated to a selected group of car parks, while the allocation of the number of locations to TAZ within the group is uniformly distributed,

- Differentially allocated to a selected group of car parks, while the allocation of the number of locations to TAZ within the group is differentiated;

- Randomly allocated of locations to all car park groups and random allocation of locations to TAZ within individual groups.

It was assumed that in the established EVCI network, in each alternative, there is an equal total number of EVCSs, complying with the legal requirements. Thus, all the obtained alternatives constitute feasible solutions.

Due to the high computational complexity associated with working on spatial data, determining the criteria values for the subsequent alternatives becomes time-consuming. Hence, in real conditions, the number of alternatives generated will usually be related to the available computational time and the expectations of the decision-maker. It is also possible to iteratively generate variants for as long as the assumed improvement of the ideal point or assumed increment in the number of Pareto-optimal solutions per 1000 generated solutions 
is being achieved. The procedure may also involve two stages. In the first stage, a smaller sample of variants for a larger number of policies is generated and pre-assessed, and in the next stage, the variants for policies selected for further analysis are additionally generated.

\subsubsection{Stage 4-Selection of an Adequate MCDA Method}

The set of alternatives generated in Stage 3 is by its nature very large. This is mainly due to the presence of multiple criteria for evaluating the alternatives and many potential sites suitable for locating new EVCI. The subsequent limitation of the set of alternatives to the set of Pareto-optimal ones merely reduces its cardinality, keeping the size of the set at the same level. For this reason, it is necessary to use an appropriate MCDA method, which will lead to the selection of a compromise solution-the most advantageous from the point of view of the decision-maker's preferences.

Whilst selecting the most suitable decision-aiding method, the convergence between the nature of the method and the decision problem should be considered carefully. The process of method selection cannot be accidental or based on its popularity in the field of study. Guitouni and Martel [87] even suggest that despite the development of a large number of MCDA methods, none can be considered as the method appropriate to all decision-making situations. The problem of selecting the most suitable MCDA method for a given decision problem type is, however, considered in the literature (e.g., [87-90]). Based on [90], a four-step procedure was applied in such a selection procedure:

- Step 1: comparative analysis of MCDA methods, including method classification, axiomatic analysis and practical applicability analysis.

- Step 2: recognition of the decision problem, including decision problem, the structure of decision problem, the availability of information, the types and character of information and the time horizon of the decision.

- Step 3: identification of the decision-maker's preferences, including the level of strategic decision, the precision of preference information, preference structure and expression, the moment of preference expression and the relation between variants in the final result.

- Step 4: comparison of results and selection of the most suitable MCDA method.

Several different MCDA methods were taken into consideration and compared while matching between the methods and the specifics of the decision problem, including the weighted linear combination, ANP, Electre III, LBS, Promethee I and UTA. As a result, the LBS method was selected for the kind of decision problem with the highest coherence. It was primarily selected in consideration of its ability to cope with a set of highly numerous alternatives and a high number of criteria, as well as the ability to make comparisons among alternatives using the natural scale of each criterion. Thus, it enables the decision-maker to better understand the problem and its potential solutions, as other methods may require rescaling the criteria values or may generate a large subset of "the best" alternatives.

\subsubsection{Stage 5-Multiple Criteria Evaluation of Alternatives}

The evaluation of alternatives and the final selection of the compromise EVCI were performed with the support of the light beam searching (LBS) method; the motivation of such a selection is provided in Section 2.3.5. The LBS method was initially proposed by Jaszkiewicz and Słowiński [91] for the problems of multiple criteria mathematical programming and subsequently adapted to the problems with a discrete set of alternatives. A detailed description of the LBS method and its application can be found in the work of Jaszkiewicz and Słowiński [92].

In each iteration of this method, a decision-maker receives a sample of nondominated points from the neighbor of the so-called middle point, which is the point generated in the previous iteration. According to Miettinen [93], an alternative is nondominated if none of the criteria can be improved without deteriorating some of the other criteria. Without any additional preference information, all nondominated alternatives are considered equally good. 
In order to define the neighborhood, the outranking relation is used. Thus, it is possible to model the preferences of the decision-maker. Specifically, the neighborhood, called the outranking neighborhood, is defined as the set of alternatives that are nondominated by the middle point. The neighborhood defined in this way does not contain points that cannot be compared with the middle point. It also does not contain points higher than the middle point, i.e., the points for which the middle point is preferred. The sample of points presented to the decision-maker consists of a middle point and the neighbor points, representing the possibility of improving individual criteria within the outranking neighborhood. Finally, a compromise solution is selected in an iterative procedure.

\section{Computational Experiment}

\subsection{Defining Potential Locations of EVCSs in the City of Poznan}

The issue of EVCS deployment was solved experimentally for the city of Poznan, which is located in the western part of Poland and has a population of about 0.5 million people. In order to determine the potential locations of EVCSs, the first step was to determine the locations of already existing stations. Two databases were used for this purpose: OpenStreetMap (OSM) and Register of Alternative Fuels Infrastructure (EIPA). The former is based on the Volunteered Geographic Information (VGI) model, and the latter is maintained by the Office of Technical Inspection-one of the Polish state institutions. Information on publicly available EVCSs is entered into it by station operators. At the time of data acquisition (January 2020), both databases were the most extensive accessible databases of EVCS locations in Poland. The analysis of the data was performed by field studies, which allowed resolving doubtful situations resulting from the data integration. Ultimately, 24 EVCSs were identified in Poznan, including 17 from the EIPA database and 7 from the OSM database (the number of EVCPs was determined at 45).

It was assumed that the new EVCSs were to be located within the currently existing car parks. The data on their locations were sourced from OpenStreetMap. As of 17 March 2020, there were 6974 areas defined as car parks within Poznan. In order to maintain the public accessibility requirement of the EVCS, car parks that did not meet this condition (e.g., private car parks, parking spaces for the disabled or parking spaces for delivery trucks) were excluded from the potential locations. The number of potential locations was eventually reduced to 5711. In addition, it was assumed that the surface area of a car park where an EVCS can be located must not be less than $200 \mathrm{~m}^{2}$, which translates into a capacity of approximately 13 parking spaces.

To divide the car parks into groups, the boundaries of the planned Clean Transport Zones in Poznan provided by the City Hall of Poznan as well as the locations of supermarkets and shopping centers from OpenStreetMap were used. The shopping centers were represented as polygons only, while supermarkets were represented as polygons or points. In order to allocate car parks to groups, buffers with the following radii were created:

- $50 \mathrm{~m}$ for clean transport zones;

- $100 \mathrm{~m}$ for shopping centers;

- $100 \mathrm{~m}$ for supermarkets as points;

- $75 \mathrm{~m}$ for supermarkets as polygons.

The maximum distances to supermarkets and shopping centers were selected so as to ensure a comfortable walking distance to shoppers' cars; i.e., they were shorter or close to the average distances of pedestrian shopping trips indicated in the literature (see, e.g., [56,84-86]).

All car parks in the assumed buffer were allocated to the clean transport zone group. For each shopping center and supermarket, the nearest car park was allocated. In the case of polygon sites, the closest car park to the centroid of the sites was considered the closest. The remaining car parks were assigned to the group of other locations.

A dbscan clustering algorithm was used to further reduce the number of possible charging station locations. The maximum distance between points was set at $300 \mathrm{~m}$. The minimum number of EVCSs in a cluster was 1 . Then for each cluster, the center of gravity 
of the points was calculated, and the car park closest to this center was selected. In this way, e.g., the parking spaces located on two sides of the street on a specific length thereof were considered one car park. The likelihood of generating solutions where multiple EVCSs were located in very close proximity to each other, which was considered undesirable, was also reduced.

The car parks within 400 meters of current charging station locations were also excluded from the analysis so that new stations would not overlap the areas already served. Eventually, 377 potential EVCS locations were considered.

The potential EVCS locations were also classified in another aspect, i.e., according to the traffic analysis zone (TAZ) class used in the transportation model of the Poznan Metropolitan Area. Three classes of TAZs were determined based on the sum of traffic production and attraction for the area (see Figure 2). The 64 TAZs with the highest values of production and attraction (40\% of the total for the city of Poznan) were categorized as Class A. Another 133 TAZs were categorized as Class B. These areas accounted for a further $40 \%$ of the traffic production and attraction in Poznan. The remaining 187 TAZs were assigned to Class $C$. These areas were characterized by the lowest values of traffic production and attraction (totaling 20\%). Table 3 shows the number of car parks classified in each group, and Figure 3 shows their geographical distribution in Poznan. The areas where no EVCSs were located are airports, lakes or green areas.

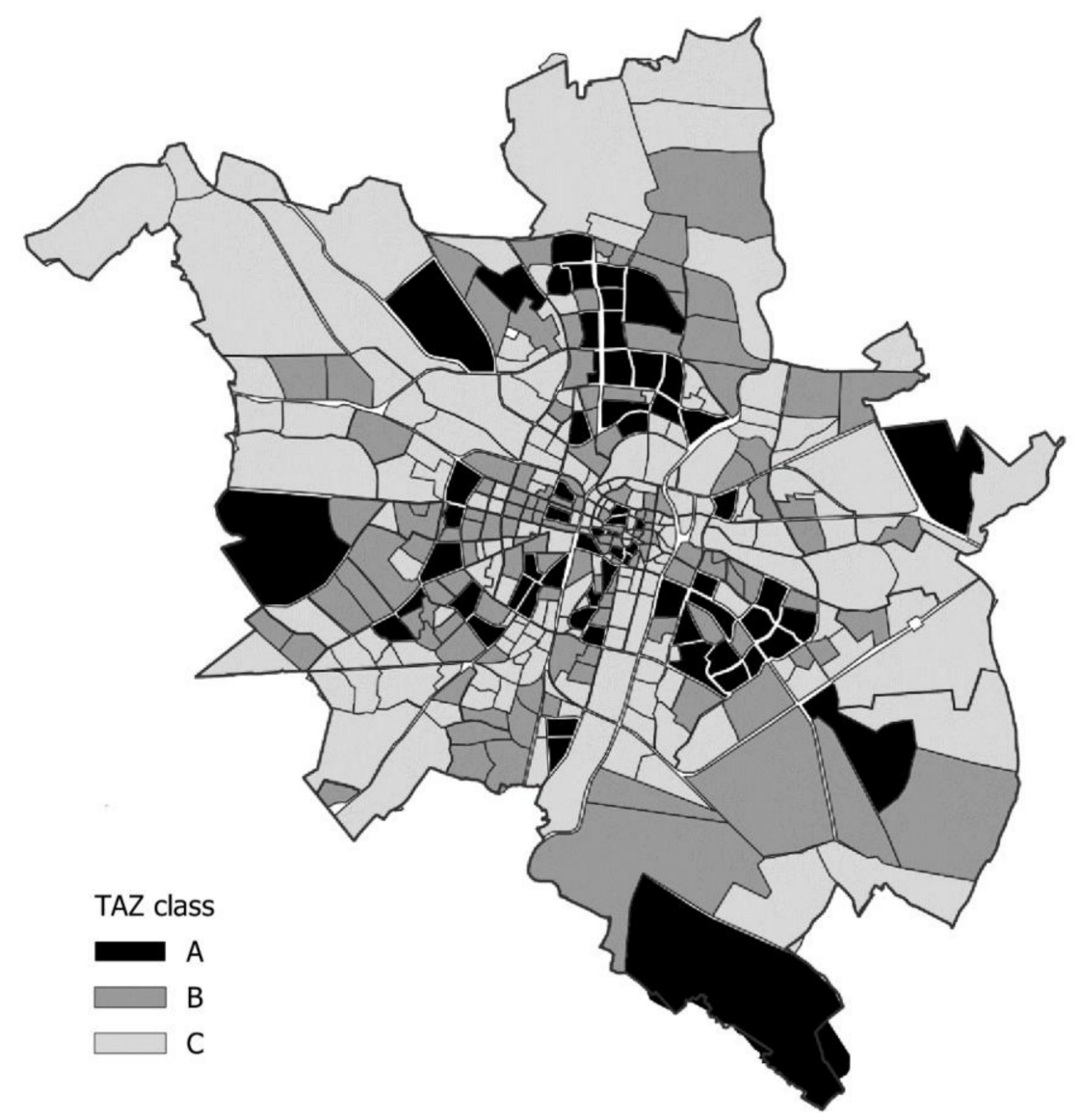

Figure 2. Classification of TAZs in Poznan. 
Table 3. The number of potential EVCS locations in each car park group in Poznan.

\begin{tabular}{ccccc}
\hline Symbol & \multicolumn{3}{c}{ Definition } & \multirow{2}{*}{ Total } \\
\cline { 2 - 4 } & A & B & C & \\
\hline 0-clean transport zone & 0 & 2 & 3 & 5 \\
1-shopping centers & 10 & 5 & 6 & 21 \\
2-supermarkets & 38 & 33 & 21 & 92 \\
3-other & 47 & 92 & 120 & 259 \\
Total & 95 & 132 & 150 & 377 \\
\hline
\end{tabular}

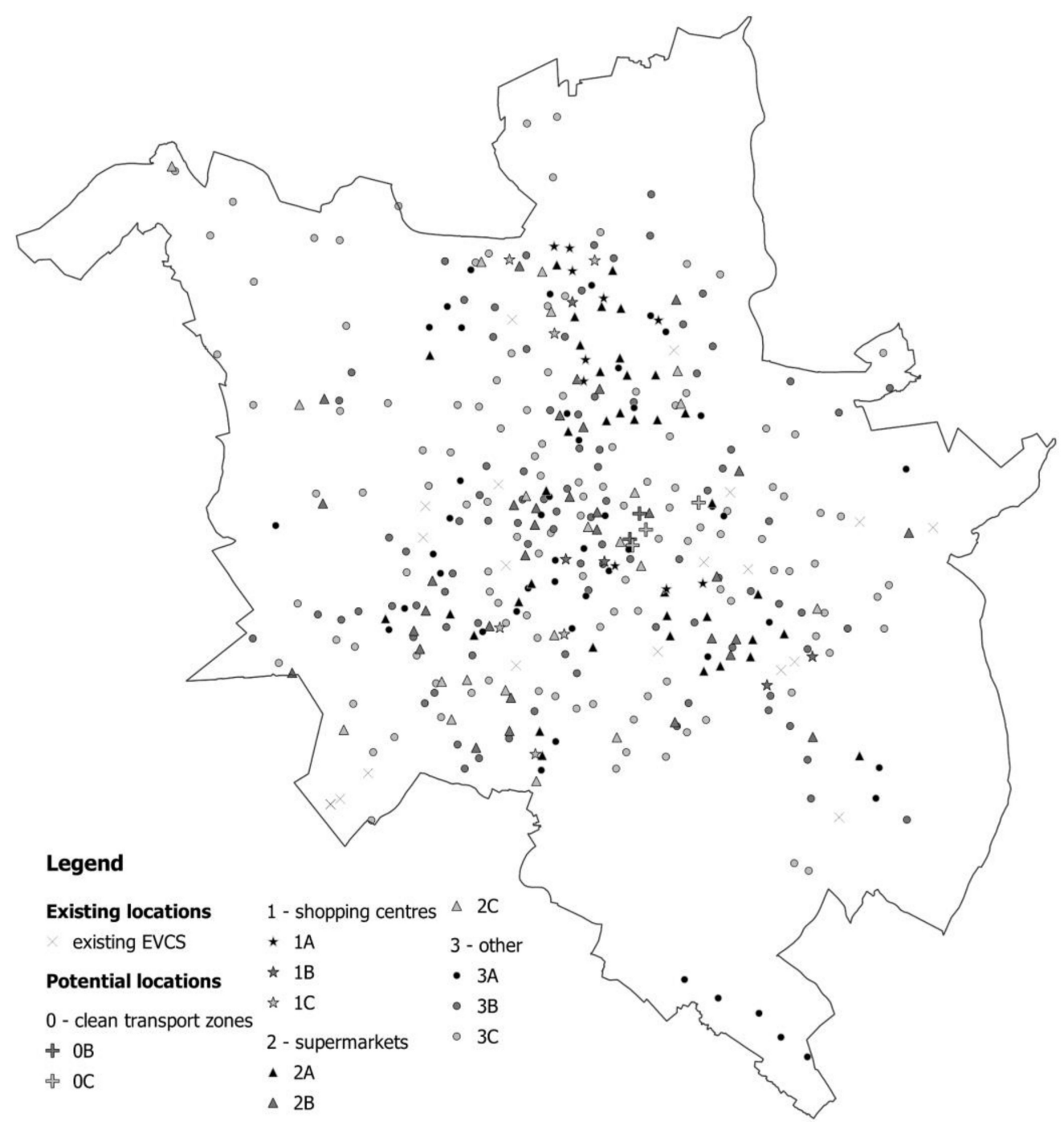

Figure 3. Locations of existing and potential EVCSs in Poznan.

The mean Euclidean distance between all 397 locations (both existing and potential) was $373.6 \mathrm{~m}$ ( $\mathrm{min} 11 \mathrm{~m}$ vs. max $1505 \mathrm{~m}$ ), a noticeable distance from the point of view of potential users choosing a particular EVCS. The smallest distance applies to two existing locations (two different EVCS operators in one car park). Moreover, distances under $100 \mathrm{~m}$ occur for four pairs of potential locations. They are related to the presence of different facilities close to each other, such as a supermarket and a shopping center, where the variants where both locations have their own dedicated charging stations were specified to be acceptable. The longest distances to the nearest station occurred in potential locations on the outskirts of the city. 


\subsection{Construction of Evaluation Criteria}

The set of eight criteria described in Section 2.3.3 was assessed. Including the subcriteria, the set included 13 elements. The data for analysis were obtained from three sources: GeoPoz, which is Poznan's cadastre and geodesic unit (C1, C2, C7), OpenStreetMap (C3, C4, C6, C8) and the transportation model of Poznan Metropolitan Area (C5). The parameters are presented in Table 4.

Table 4. Parameters for a considered family of criteria—applied for Poznan.

\begin{tabular}{ccc}
\hline Criterion & Subcriterion & Parameters \\
\hline C1 & $C 1.1$ & $l=400 \mathrm{~m}, S_{p}^{I}=288$ stops \\
& $C 1.2$ & $l=400 \mathrm{~m}, S_{p}^{I I}=1029$ stops \\
C2 & $C 2.1$ & $l^{h p}=400 \mathrm{~m}, R=2816$ zones \\
& $\mathrm{C} 2.2$ & $l^{l p}=800 \mathrm{~m}, R=2816$ zones \\
C3 & $\mathrm{C} 3.1$ & $l^{h p}=200 \mathrm{~m}, S=51$ arcs \\
& $\mathrm{C} 3.2$ & $l^{l p}=400 \mathrm{~m}, S=51$ arcs \\
C4 & - & $U=254$ zones \\
C5 & $C 5.1$ & $\gamma=64$ TAZs \\
& $C 5.2$ & $J=384$ TAZs \\
C6 & $C 5.3$ & $l=100 \mathrm{~m}, N=2721$ stores \\
C7 & - & $l=100 \mathrm{~m}, L=61,878$ points \\
C8 & - &
\end{tabular}

Criterion $\mathrm{C} 1$ assessed the integration of EVCI with tram and bus stops. Integrated tram/bus stops were included in the computation of both networks. A total of 288 stops were included in the tram network, and 1029 stops were included in the bus network (see Figure 4a). In both subcriteria, the maximum distance from the nearest EVCS was set at $400 \mathrm{~m}$.

Criterion C2 assessed the working-age population that lived within $400 \mathrm{~m}$ (C2.1) or within $800 \mathrm{~m}(\mathrm{C} 2.2)$ of the nearest EVCS. The computation was made considering the city block level of details. In Poznan, there were 2816 such blocks inhabited by 250,400 workingage residents (ca. $51 \%$ of all inhabitants in Poznan) (see Figure $4 \mathrm{~b}$ ).

Criterion C3 assessed the number of EVCSs located near the main roads in Poznan. Primary, secondary and trunk roads were considered. Motorways were excluded as, in the case of Poznan, they serve mainly nonurban (transit) traffic and should be served by EVCSs located in rest areas. After generalization, the network of these roads consisted of 51 arcs. Within a $200 \mathrm{~m}$ radius (C3.1), there are nine existing EVCSs and 123 potential locations. Within a $400 \mathrm{~m}$ radius (C3.2), there are 14 existing EVCSs and 198 potential locations (see Figure 4c). 


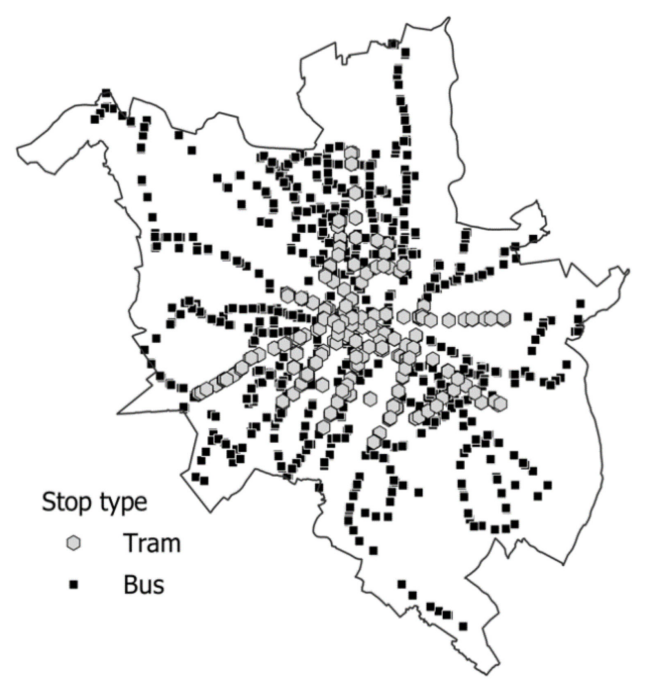

(a)

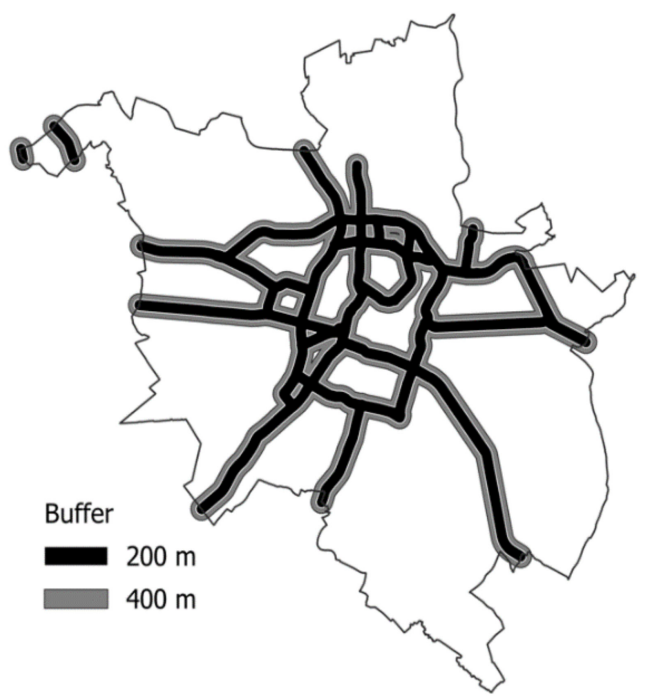

(c)

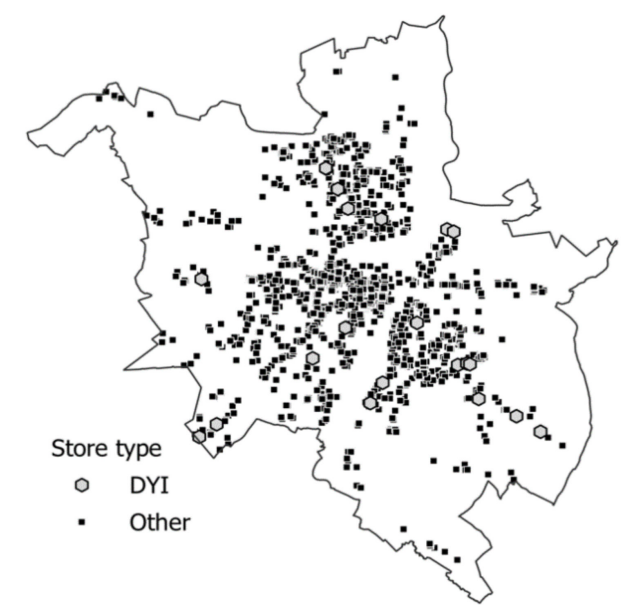

(e)

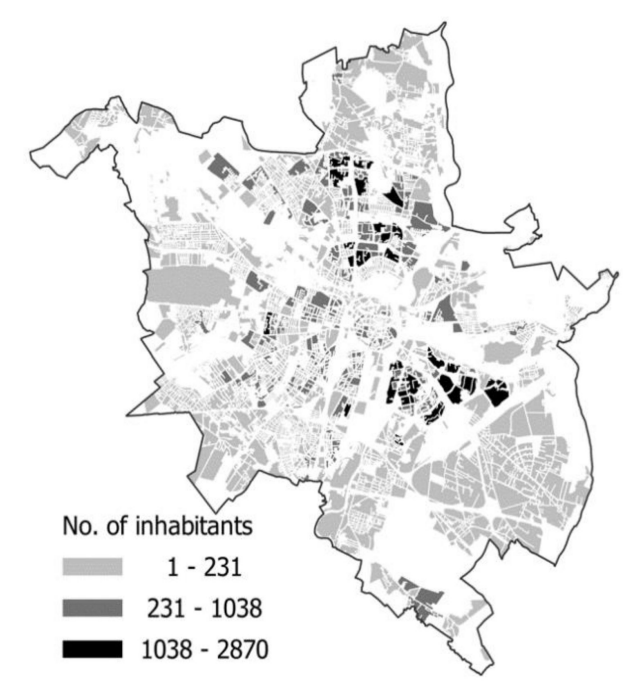

(b)

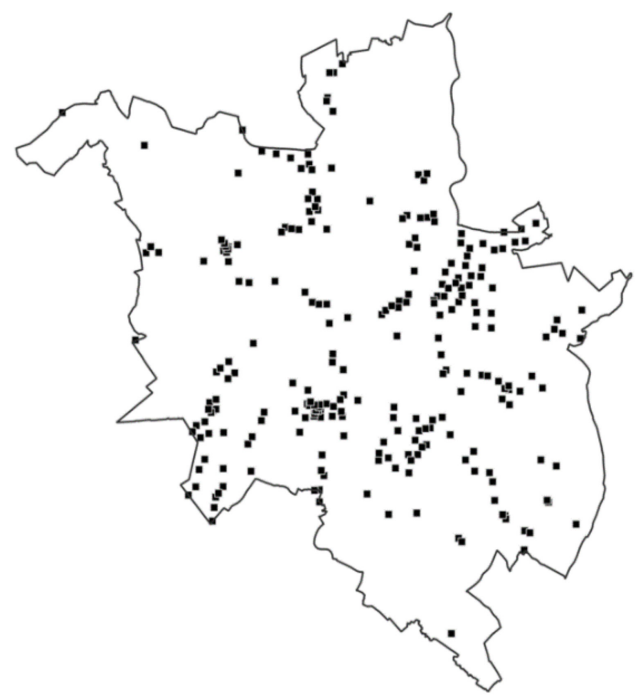

(d)

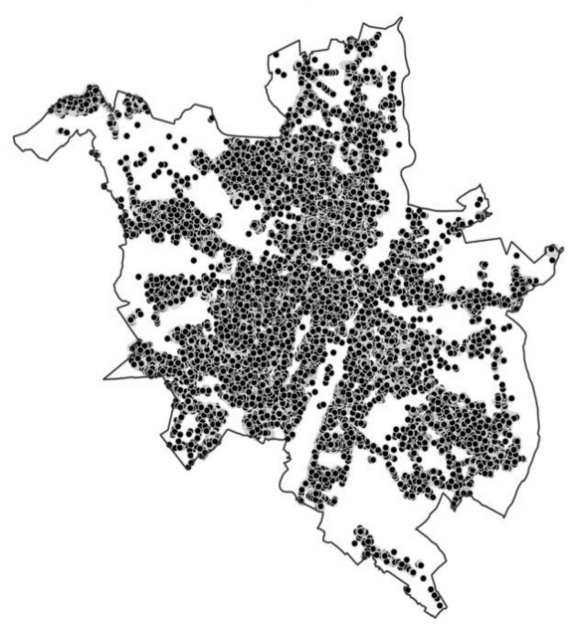

(f)

Figure 4. Data utilized during the computation of value of each criterion: (a) C1—tram and bus stop locations; (b) C2-city blocks inhabited by at least one working-age person; (c) C3-primary road system in Poznan, with 200 and 400 m buffers; (d) C4—centroids of industrial areas; (e) C6 and C8—store locations, including DYI stores; (f) C7—address point locations. 
In criterion $\mathrm{C} 5$, the same division of TAZs was used as in the clustering of potential EVCS sites (see Figure 2). In addition, 254 industrial areas (C4, Figure 4d), 2721 stores (C6, Figure 4e), 21 DYI stores (C8, Figure 4e) and 61,878 address points (C7, Figure 4f) were included in Poznan. In criteria C5, C7 and C8, the maximum distance was set at $400 \mathrm{~m}$. In the case of 66 , it was $100 \mathrm{~m}$.

In order to assess compliance with the maximum distance requirement, buffers were generated in the GIS. Before determining each variant's criteria values, these buffers were dissolved to avoid multiple counts of the same objects within the range of multiple EVCSs.

\subsection{Generating Alternatives}

According to the requirements of the Act on Electromobility and Alternative Fuels, there should be at least 210 EVCPs in Poznan by the end of December 2020. All of the generated variants contained this number of points as a target. Each variant added 165 EVCPs, which translated into 73 EVCSs, as it was assumed that one EVCS consists of 2.26 EVCPs on average. This means, that there are $1.5136 \times 10^{79}$ potential solutions to the problem (73 combinations of EVCSs from 377 potential locations).

Twenty-seven variant draw policies were proposed, out of which 26 indicated the number of drawn EVCS locations in each car park group. The exact values are shown in Table A2 (Appendix B). Under policy P27, the division of car parks into groups was ignored, drawing 68 out of 372 potential locations. Five potential locations belonging to the clean transport zones groups were considered mandatory and were included in each policy.

The first step was to generate at least 4001 alternatives for each of policies P1-P26 and 8002 alternatives for policy P27. Due to technical problems occurring with the hardware, in some cases, the generated number of alternatives was slightly higher (see Table 5). QGIS 3.14 software was used to generate the alternatives and calculate the criteria values for them. A single alternative was generated on average in $46 \mathrm{~s}$ by the Xeon W-2145 machine. In the case of policy P27, due to the simplification of the generation procedure, the generation time amounted to $37 \mathrm{~s}$.

Table 5. Parameters for a considered family of criteria.

\begin{tabular}{ccccccccccccccc}
\hline P1 & P2 & P3 & P4 & P5 & P6 & P7 & P8 & P9 & P10 & P11 & P12 & P13 & P14 \\
\hline 4177 & 4185 & 4078 & 4178 & 4169 & 4177 & 4165 & 4171 & 4170 & 4163 & 4031 & 4175 & 4171 & 4166 \\
\hline P15 & P16 & P17 & P18 & P19 & P20 & P21 & P22 & P23 & P24 & P25 & P26 & P27 & Total \\
\hline 4468 & 4003 & 4003 & 4003 & 4003 & 4001 & 4003 & 4002 & 4002 & 4002 & 4659 & 4001 & 8002 & 115,328 \\
\hline
\end{tabular}

In the next step, medians of the obtained criteria (Table A3), their best values (Table A4) and standard deviations (Table A5) were determined for each policy. A preliminary analysis of the best values for policy P27 indicated that, despite generating almost twice as many variants as each of the other policies, the best values obtained by this policy equaled the results obtained by the other policies only for criterion $\mathrm{C} 8$. For criterion $\mathrm{C} 5$, the results obtained were worse by 31-41\%, and for criterion C6, defining the link between EVCI networks and stores, the results obtained were worse by $24 \%$. A deterioration of $10 \%$ or more also occurred for criteria C2.1, C3.1 and C7. The above results point to the importance of using policies to narrow down the searchable set of acceptable solutions.

Furthermore, the median analysis indicated, among other things, that:

- Increasing the number of points drawn near shopping centers at the expense of supermarkets improves the value of criterion C6 while worsening C7 because shopping centers usually contain many shops while being assigned to one address point, while supermarkets may be located among other developments.

- Increasing the number of EVCSs drawn within specific TAZ classes increases the coverage by these TAZ classes. Still, some potential EVCS locations are on the border of TAZs of different classes. Hence, retaining criterion C5 in the criteria set may have some value for the decision-maker. 
- The emphasis on drawing the points in TAZ class $C$ results in the best values for criterion $\mathrm{C} 4$, but at the expense of a significant deterioration in the values of the remaining criteria, except C5.3.

It was also found that $57.37 \%(57,971$ of 115,328$)$ were Pareto-optimal alternatives.

Based on the above analyses, it was decided to generate an additional 8000 alternatives for policy P4 and 32,221 alternatives for policy P22. The expanded sets were named P4x and P22x, respectively. The increase in the number of alternatives generated for both policies resulted in a slight increase in the best criteria values (see Table A4). In both cases, the improvement affected 9-10 criteria and averaged $2 \%$. One exception was criterion C4, whose best value improved by $7.3 \%$ in policy P22x-the mean distance to industrial zones decreased from 763 to $711 \mathrm{~m}$.

The median result did not change significantly. It was $<1 \%$ for each criterion (see Table A3). The standard deviations were also similarly slightly changed, i.e., $<2 \%$ for all criteria except C8 in policy P22x, where it was $<3 \%$ (see Table A5).

When these were considered with the additional alternatives, the total number increased to 155,549. All the alternatives were unique. Table 6 shows the ideal, nadir and median points for the entire set of alternatives.

Table 6. Ideal, nadir and median criteria values for all 155,549 alternatives.

\begin{tabular}{lccccccccccccc}
\hline Point & C1.1 & C1.2 & C2.1 & C2.2 & C3.1 & C3.2 & C4 & C5.1 & C5.2 & C5.3 & C6 & C7 & C8 \\
\hline ideal & 181 & 387 & 126,693 & 212,120 & 50 & 65 & 596 & 42.3 & 32.4 & 21.1 & 479 & 1447 & 17 \\
nadir & 74 & 209 & 41,703 & 133,082 & 19 & 34 & 1249 & 4.2 & 9.4 & 4.7 & 93 & 494 & 5 \\
median & 133 & 311 & 95,707 & 191,531 & 33 & 50 & 913 & 22.9 & 17.0 & 8.0 & 263 & 1085 & 10 \\
\hline
\end{tabular}

The number of Pareto-optimal alternatives was 71,599, i.e., $46.03 \%$. Increasing the number of generated alternatives by 40,221 resulted in an increase in Pareto-optimal alternatives by only 13,627 ( $34 \%$ of alternatives were Pareto-optimal). Due to time constraints and relatively small increments of nondominated alternatives and best criteria values, no further iteration of alternative generation was attempted.

\subsection{Results}

Due to the large number of alternatives generated (a total of 155,549 alternatives), Light Beam Search 0.99 software was used to select the compromise solution. The software allows for a dialogue (interactive) selection procedure of the compromise solution based on the defined preference model. The calculation phase is intertwined with the decisionmaking phase.

The first phase involved a procedure for filtering out dominant variants. The selected 6 out of 286 three-dimensional visualizations of Pareto-optimal alternatives are presented in Figure 5. The axes on the diagrams indicate the values of criteria or subcriteria-3 selected from 13. A single point on each of the diagrams indicates one generated solution with specific values of defined criteria and subcriteria. As can be seen, depending on the adopted criteria and subcriteria, the space of Pareto-optimal solutions has a different shape.

Correlation analysis of all criteria and subcriteria was performed for the set of 71,599 solutions in the next step. The obtained values are summarized in Table 7. As can be observed:

- The highest positive correlation occurs between C5.1 and C2.1 (0.84), and a negative correlation occurs between C5.3 and C2.1 (-0.89).

- In 4 cases out of 78 , the correlation value of criteria and subcriteria in absolute terms is 0.80 or more.

- In 49 cases out of 78, the correlation value of criteria and subcriteria in absolute value does not exceed 0.50 . 
The correlation analysis confirms the appropriateness of selecting a set of criteria evaluating individual policies due to their high independence. Similar analyses were also conducted for sets of 58,000 115,000 and 155,000 alternatives. The correlation values remained stable.

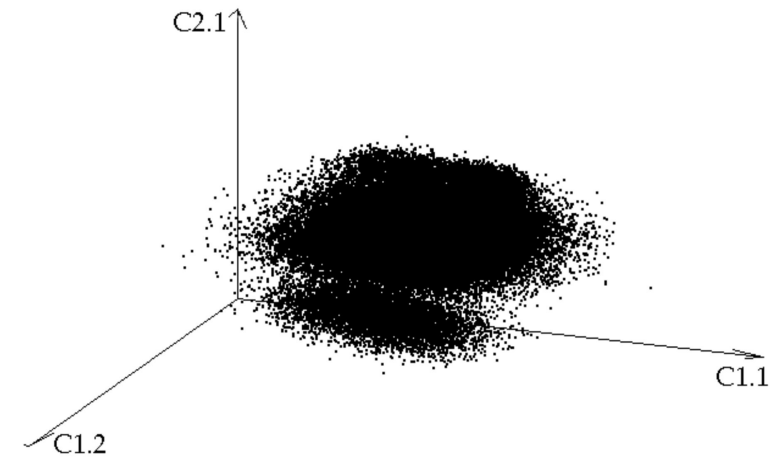

(a)

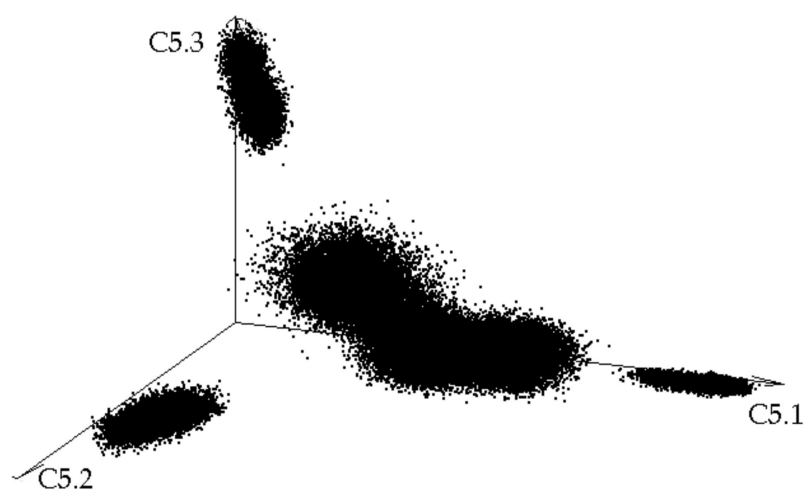

(c)

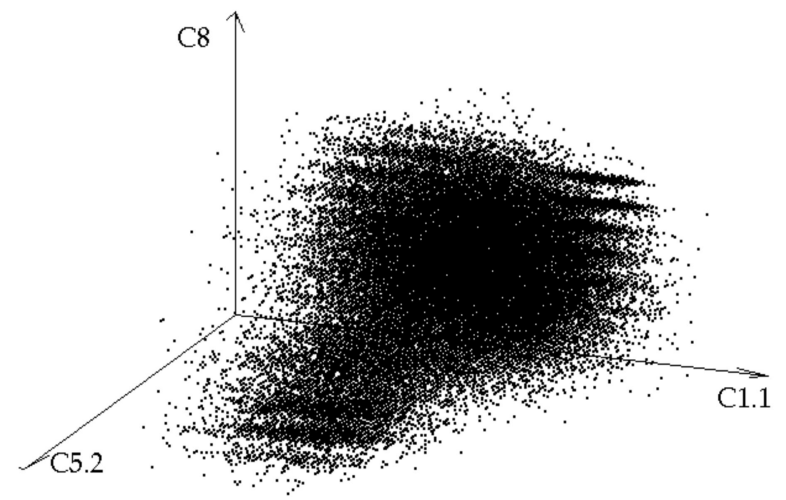

(e)

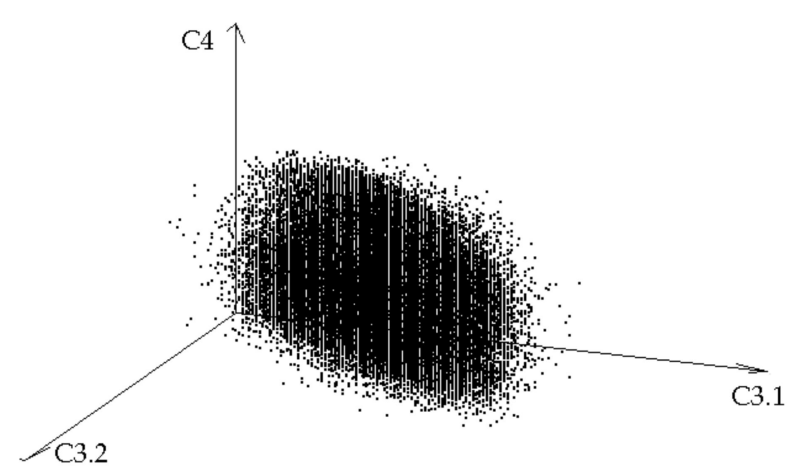

(b)

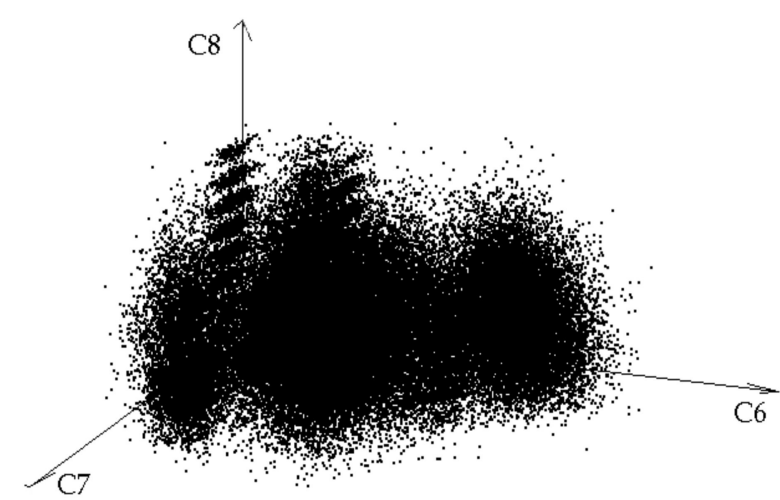

(d)

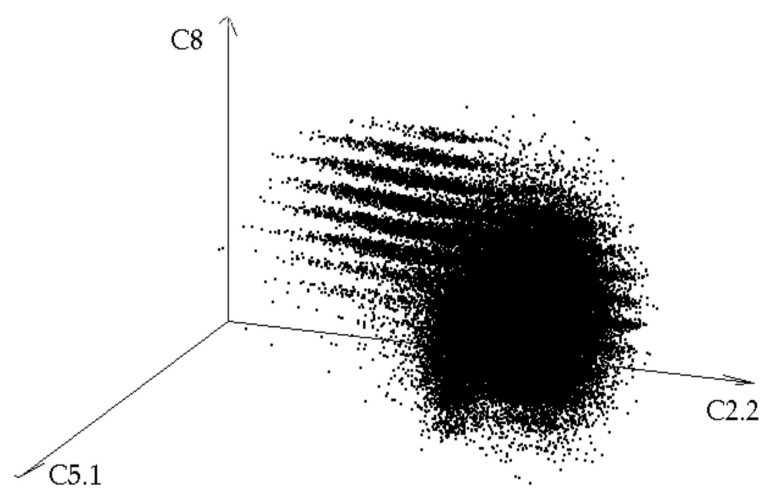

(f)

Figure 5. Selected 3D visualization of criteria values of the set of 71,599 Pareto-optimal alternatives: (a) $X$ axis—criterion C1.1, Y-C1.2, Z-C2.1; (b) X axis-criterion C3.1, Y-C3.2, Z-C4; (c) X axis-criterion C5.1, Y-C5.2, Z-C5.3; (d) X axis-criterion $\mathrm{C} 6, \mathrm{Y}-\mathrm{C} 7, \mathrm{Z}-\mathrm{C} 8$; (e) $\mathrm{X}$ axis-criterion $\mathrm{C} 1.1, \mathrm{Y}-\mathrm{C} 2.1, \mathrm{Z}-\mathrm{C} 8$; (f) $\mathrm{X}$ axis-criterion $\mathrm{C} 2.2, \mathrm{Y}-\mathrm{C} 5.1, \mathrm{Z}-\mathrm{C} 8$. 
In the next step, the middle point (middle point 1) was computed for the 71,599 Paretooptimal alternatives analyzed, where the decision-maker's preferences were entered as:

- Threshold values: indifference $q$ and preference $p r$ (both for all criteria) and veto $v e$ (for criterion C8);

- Maximum values (for minimized criterion C4) and minimum values (for the remaining criteria that are maximized) and variation ranges;

- $\quad$ Reference point.

In this way, it was possible to calculate middle point 2 . The adopted and computed values of the dialogue procedure of the LBS method are summarized in Table 8.

Table 7. Correlation on criteria-Pareto-optimal 71,599 solutions.

\begin{tabular}{|c|c|c|c|c|c|c|c|c|c|c|c|c|}
\hline Criterion & C1.1 & C1.2 & C2.1 & $\mathrm{C} 2.2$ & C3.1 & C3.2 & $\mathrm{C} 4$ & C5.1 & C5.2 & C5.3 & C6 & $\mathrm{C} 7$ \\
\hline C1.2 & 0.55 & & & & & & & & & & & \\
\hline $\mathrm{C} 2.1$ & 0.58 & 0.73 & & & & & & & & & & \\
\hline $\mathrm{C} 2.2$ & 0.46 & 0.67 & 0.83 & & & & & & & & & \\
\hline C3.1 & 0.05 & 0.14 & -0.02 & -0.04 & & & & & & & & \\
\hline C 3.2 & 0.25 & 0.37 & 0.31 & 0.21 & 0.71 & & & & & & & \\
\hline $\mathrm{C} 4$ & 0.57 & 0.58 & 0.79 & 0.53 & 0.09 & 0.35 & & & & & & \\
\hline C5.1 & 0.54 & 0.50 & 0.84 & 0.65 & -0.06 & 0.18 & 0.76 & & & & & \\
\hline C5.2 & -0.11 & 0.16 & 0.00 & 0.16 & -0.17 & 0.00 & -0.19 & -0.42 & & & & \\
\hline C5.3 & -0.49 & -0.68 & -0.89 & -0.77 & 0.06 & -0.31 & -0.71 & -0.58 & -0.34 & & & \\
\hline $\mathrm{C} 6$ & 0.42 & 0.60 & 0.60 & 0.49 & 0.46 & 0.48 & 0.57 & 0.47 & -0.13 & -0.52 & & \\
\hline $\mathrm{C} 7$ & 0.41 & 0.51 & 0.79 & 0.65 & -0.31 & 0.06 & 0.63 & 0.65 & 0.23 & -0.83 & 0.25 & \\
\hline $\mathrm{C} 8$ & 0.15 & 0.12 & 0.12 & 0.07 & 0.16 & 0.11 & 0.20 & 0.29 & -0.44 & 0.02 & 0.25 & -0.04 \\
\hline
\end{tabular}

Table 8. Thresholds for the model of preference, middle and reference points (for Pareto-optimal alternatives).

\begin{tabular}{|c|c|c|c|c|c|c|c|c|}
\hline \multirow{2}{*}{ Criterion } & \multicolumn{5}{|c|}{ Thresholds $^{1}$} & \multirow{2}{*}{$\begin{array}{l}\text { Middle } \\
\text { Point } 1\end{array}$} & \multirow{2}{*}{$\begin{array}{c}\text { Reference } \\
\text { Point }\end{array}$} & \multirow{2}{*}{$\begin{array}{l}\text { Middle } \\
\text { Point } 2\end{array}$} \\
\hline & $\min$ & $\max$ & $q$ & $p r$ & $v e$ & & & \\
\hline C1.2 & 150 & 181 & 10 & 30 & - & 123 & 150 & 154 \\
\hline $\mathrm{C} 2.1$ & 300 & 382 & 10 & 30 & - & 314 & 300 & 305 \\
\hline $\mathrm{C} 2.2$ & 67,000 & 126,693 & 100 & 55,000 & - & 91,933 & 100,000 & 89,658 \\
\hline C3.1 & 156,000 & 212,120 & 10,000 & 30,000 & - & 195,252 & 180,000 & 182,053 \\
\hline C 3.2 & 28 & 50 & 5 & 10 & - & 36 & 40 & 30 \\
\hline $\mathrm{C} 4$ & 43 & 65 & 5 & 10 & - & 53 & 50 & 48 \\
\hline C5.1 & 596 & 1045 & 200 & 300 & - & 829 & 900 & 936 \\
\hline C5.2 & 15.0 & 42.3 & 5.0 & 12.0 & - & 19.1 & 30.0 & 17.5 \\
\hline C5.3 & 16.0 & 32.4 & 5.0 & 10.0 & - & 18.5 & 25.0 & 16.6 \\
\hline C6 & 10 & 21.1 & 5.0 & 8.0 & - & 11.7 & 15.0 & 10.8 \\
\hline $\mathrm{C} 7$ & 208 & 479 & 30 & 60 & - & 249 & 280 & 234 \\
\hline $\mathrm{C} 8$ & 1200 & 1447 & 50 & 100 & 200 & 1062 & 1200 & 1235 \\
\hline
\end{tabular}

${ }^{1}$ Thresholds: indifference- $q$, preference- $p r$, veto—ve.

As a result, two generated policies, p9-a02906 and p27-a02618, turned out to be the neighboring points to the middle point. The comparative comparison of particular criteria from $\mathrm{C} 1$ to $\mathrm{C} 8$ for two proposals of electric vehicle charging stations' location is presented in Figure 6. As can be seen, these alternatives are diversified to the greatest extent, and the only criterion whose value is the same is C3.2 (it is 51). 


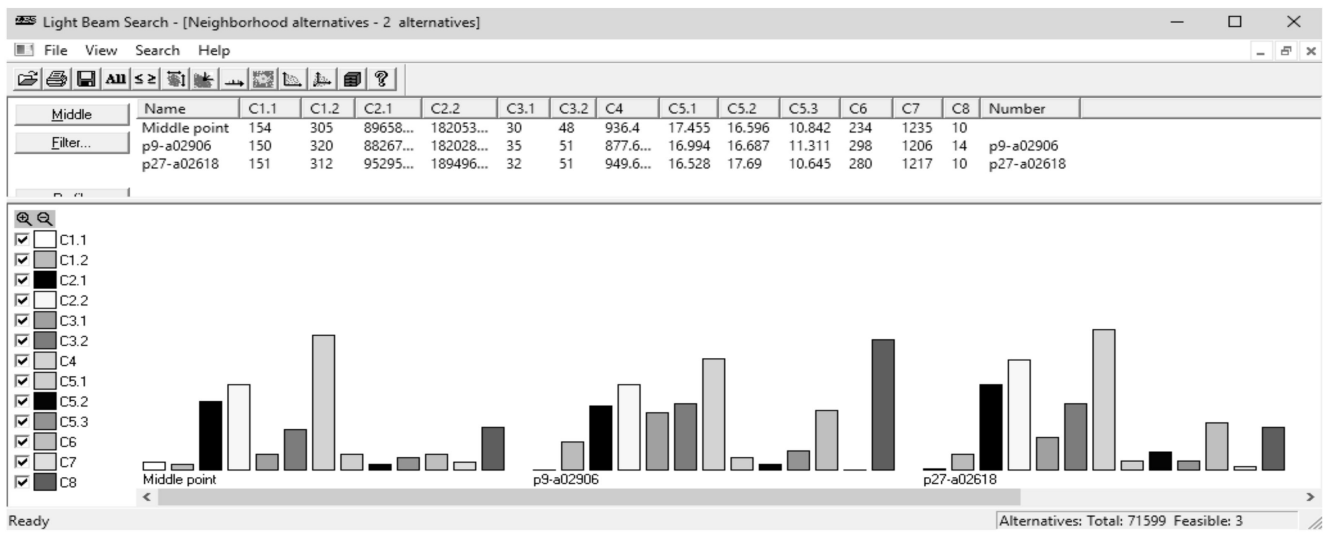

Figure 6. The visualization of results of the final LBS procedure: middle point, p9-a2906 and p27-a2618.

The geographical layout of the EVCSs for both alternatives is shown in Figure 7. It varies in terms of coverage of specific parts of the city. Good geographical coverage of the whole city, including noncritical areas, would require the use of more EVCSs.

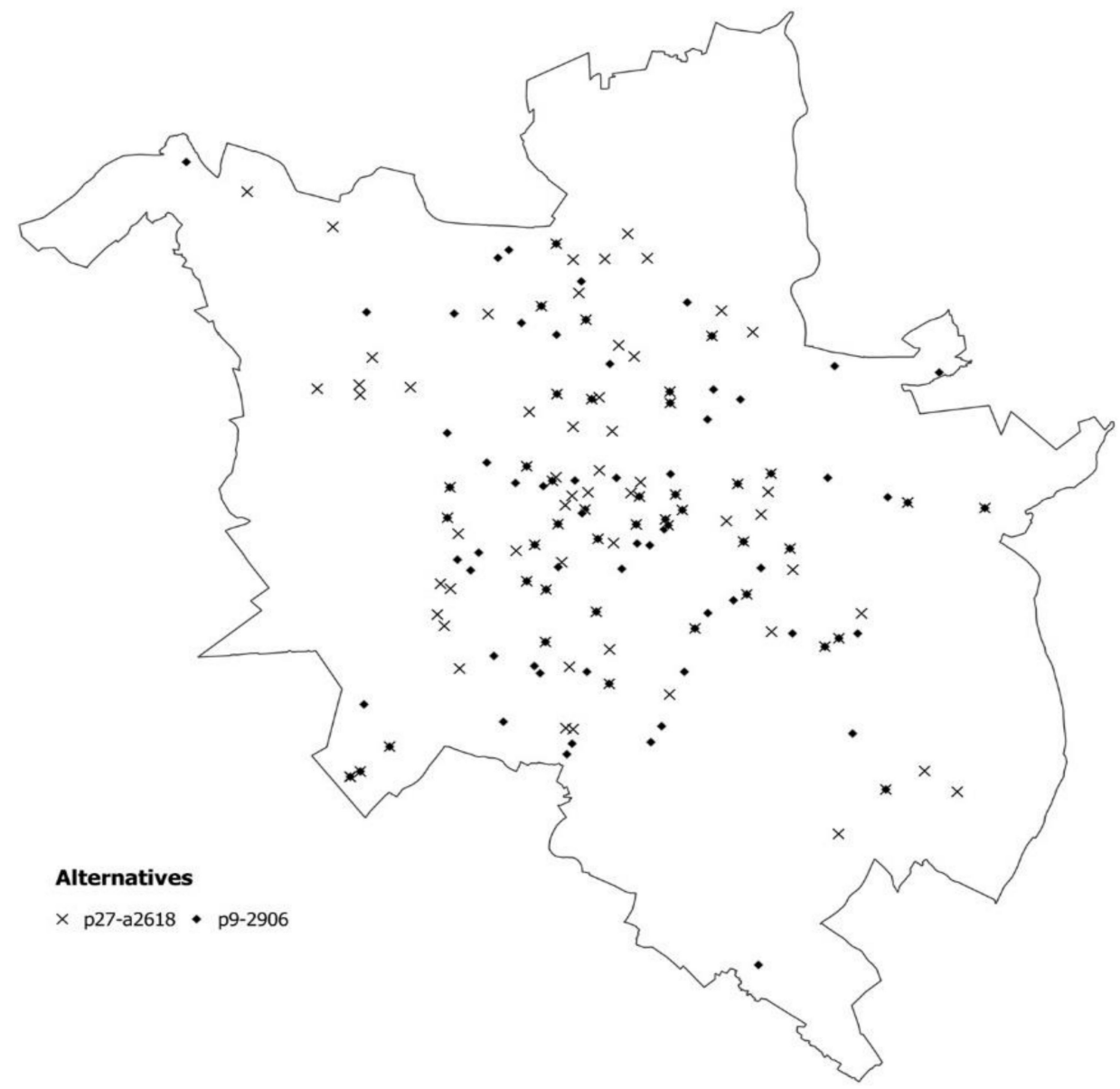

Figure 7. Location of EVCSs in compromise solutions p9-a2906 and p27-a2618 selected in interactive LBS procedure. 


\section{Discussion and Conclusions}

\subsection{The Result of the Research}

This paper proposes a methodology for EVCI planning for urban areas on a microscale, using the existing parking spaces and considering the previously established and functioning EVCSs. The developed methodology has a universal character-it can be applied in different cities around the world. However, due to the varying availability of data and the cities' specificities, modifications to the detailed procedures for dividing car parks into groups or determining the values of criteria, or even within the family of criteria itself, may be required. For example, Euclidean distances were used in all calculations in the considered case study of the city of Poznan. This has to do with the fact that it is difficult to determine accurate distances in pedestrian traffic. The difficulty arises from the high demand for data concerning potential shortcuts (also unofficial) and barriers (fences, hedges, etc.). Even minor errors such as lack of information on pedestrian crossings, for example, may cause significant changes in the length of the mapped routes, resulting in changes in the service areas. In the case of Poznan, the quality of available data was considered insufficient, based on the assessment made within the travel planner analysis (see [94,95]). However, the proposed approach does not exclude the possibility of calculating distances measured along the transport network, provided that data with a sufficient precision level are available.

It is noteworthy that the input data for the analysis are dynamic and dependent on factors such as investments and renovations in progress or the city's current economic situation. Therefore, the results obtained could slightly differ if the analyses were conducted at a different point in time or if other assumptions were made concerning the planned investments. The proposed methodology makes it possible to repeat the analysis assuming that some or all of the existing EVCSs remain in their current location and those that are in unsatisfactory locations at a given point in time are removed or added to the pool of potential locations.

The proposed evaluation criteria allow taking into account the mutual impact of EVCSs. Most criteria do not favor a high density of EVCSs, while criterion C4 seeks an optimal distribution of the network relative to industrial areas. Simultaneously, many of the adopted criteria allow for considering the deployment of EVCSs from the viewpoint of passenger EV and e-LCV users ( $\mathrm{C} 1-\mathrm{C} 3, \mathrm{C} 5$ and $\mathrm{C} 6)$, and the remaining ones $(\mathrm{C} 4, \mathrm{C} 7$ and C8) are mainly from the point of view of e-LCV users.

The interactive LBS method used to solve the problem enables the methodology to be applied in a more participative environment. Each stakeholder can search for solutions that best suit their preferences that may also be formulated at the stage of creating policies for the distribution of EVCSs among different parking groups.

\subsection{Objective of the Research}

The authors developed 5MAGISEV, a comprehensive EVCI-shaping methodology based on generating a large set of alternatives (alternative EVCS configurations), taking into account the already existing stations and assuming interactions between the designated points. The generation of alternatives is based on policies for selecting specific alternative locations, with each solution meeting the fundamental constraint of a predetermined total (minimum) number of ECVSs. The selection of a solution takes place in two stages. While the first stage consists of filtering out Pareto-optimal solutions, the second one is an interactive review of the remaining set of solutions considering the decision-maker's preference model. The finally selected solution is a compromise of all the evaluation criteria considered.

The proposed methodology for the construction of EVCI was experimentally verified. On the one hand, this allowed proving its correctness, and on the other hand, it led to solving the problem of determining the target configuration of EVCI for the Poznan agglomeration, where such issues are at a relatively early stage of development. There were only 24 ECVSs for the area inhabited by over 500,000 people. The developed methodology 
is universal and may be used in other regions, assuming, however, that the following boundary conditions are met:

- There is a public transport system in the area under consideration with clearly separated primary and secondary roles; in the absence of separation, criteria C1.1 and C1.2 should be reduced to a single form- $\mathrm{C} 1$.

- There is a division of the analyzed area into TAZs, within which three separate classes with clearly different levels of traffic production and attraction can be distinguished; in the case of a different division, it is necessary to modify the form of criterion C 5 from the current form C5.1-C5.3 to one corresponding to a different division of the classes.

- The target number of EVCSs necessary for efficient use of electric vehicles in the analyzed area is known; in the absence of such information, it is necessary to conduct a supplementary analysis or adopt a value resulting from local authorities' financial capabilities.

It should be also noted that the list of parking groups and their hierarchization should be customized according to the city's needs; therefore, such a list may be different from the one presented in Section 2.3.2.

\subsection{Further Steps}

Considering the current assumptions underlying the developed methodology, the authors see the need for its further development. Plans are made to consider the option of a varying number of EVCSs within the generated alternatives. However, this requires the inclusion of additional criteria, such as those of an economic nature. Furthermore, it is assumed that the policies for allocating EVCSs to parking groups indicate their exact number to be allocated to each group. It may be worth developing the possibility to formulate these policies with phrases such as "at least/no more than $\mathrm{x} \%$ of EVCPs are located at the car parks of a given group".

Author Contributions: Conceptualization, M.S. and P.Z.-T.; methodology, M.S. and P.Z.-T.; software, M.S., P.Z.-T. and M.K.; validation, P.Z.-T.; formal analysis, M.S. and P.Z.-T.; investigation, M.S., P.Z.-T. and M.K.; resources, M.S., P.Z.-T. and M.K.; data curation, M.S., P.Z.-T. and K.L.; writingoriginal draft preparation, M.S., P.Z.-T., P.S. and M.K.; writing—review and editing, P.Z.-T., P.S. and M.K.; visualization, P.Z.-T., M.K. and P.S.; supervision, P.S.; project administration, P.Z.-T.; funding acquisition, P.S. All authors have read and agreed to the published version of the manuscript.

Funding: This research was funded by the Ministry of Education and Science at the Poznan University of Technology, grant title: Management of land transport systems in the aspect of their efficiency and safety, grant number 0416/SBAD/0002.

Institutional Review Board Statement: Not applicable.

Informed Consent Statement: Not applicable.

Data Availability Statement: Publicly available datasets were analyzed in this study. This data can be found here: https:/ / eipa.udt.gov.pl/ (accessed on 30 May 2021), https://bip.poznan.pl/bip/uchwaly/ xxxv-623-viii-2020-z-dnia-2020-09-29,82666/ (accessed on 30 May 2021), www.openstreetmap.org/ (accessed on 30 May 2021), http:/ /sip.geopoz.pl/sip/uslugi/get_uslugi/ (accessed on 30 May 2021). The transportation model of Poznan Metropolitan Area is publicly available on request from the Poznań City Hall.

Conflicts of Interest: The authors declare no conflict of interest. 


\section{Appendix A}

Table A1. The register of key research on EVCS location decision problem.

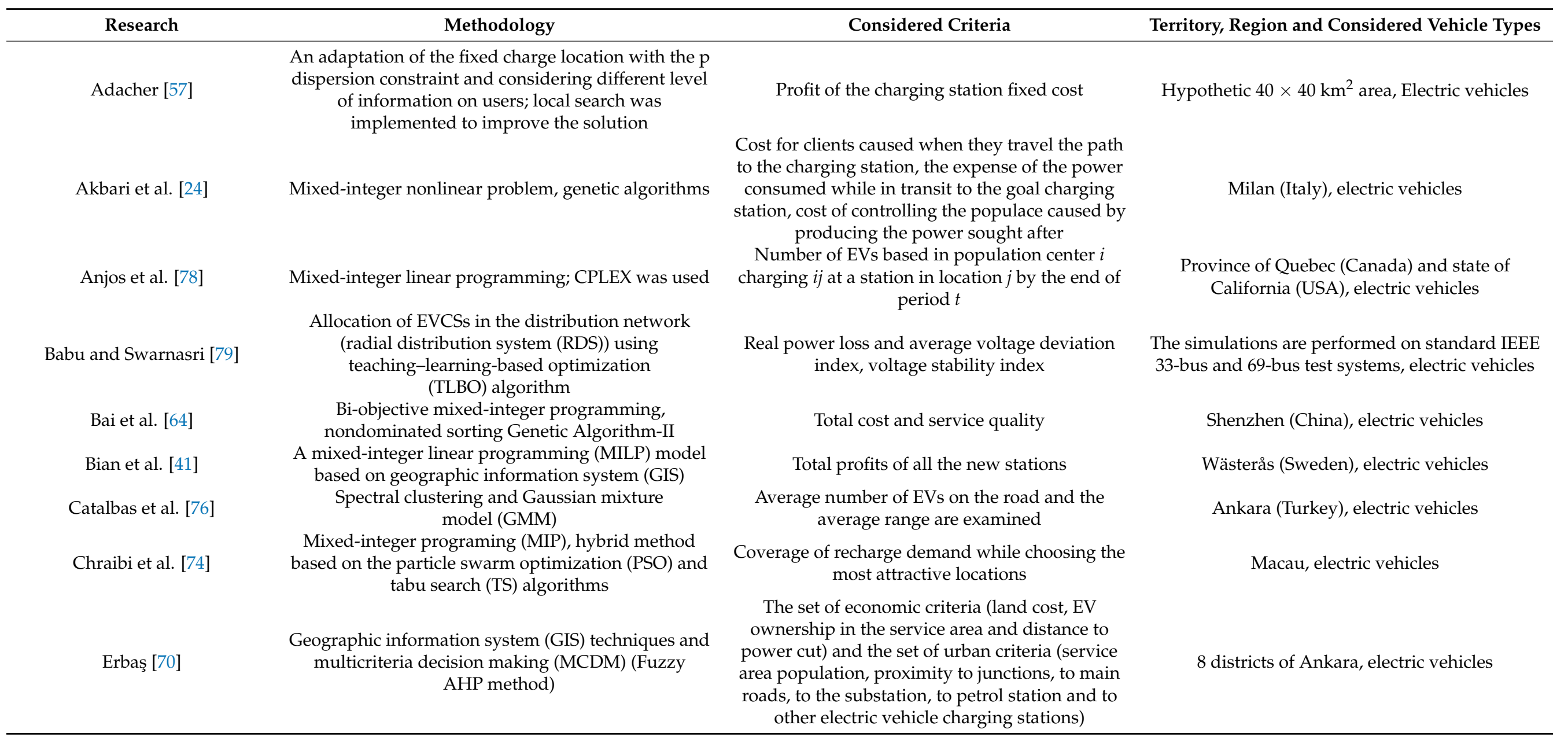


Table A1. Cont.

Research

Methodology

Multicriteria decision making (MCDM) based on the

linguistic entropy weight (LEW) method and fuzzy axiomatic design (FAD)

Gao et al. [75]

Gong et al. [39]

Guler and Yomralioglu [40]

Guo and Zhao [69]

Haiyang et al. [42]

Harighi et al. [46]

Huang and Kackelman [59]
Multicriteria decision making (MCDM) (fuzzy TOPSIS method)

A mixed-integer nonlinear programing and heuristic algorithm

Nondeterministic polynomial (NP) model, an agent-based model to simulate the optimized charging station location based on Anylogic

Geographic information system (GIS) techniques and multicriteria decision making (MCDM) (fuzzy AHP method)

$$
\text { TOPSIS method) }
$$

Mixed-integer linear programming (MILP) mode based on geographic information system (GIS)

Mixed-integer programming, genetic algorithms

Bi-level optimization problem, genetic algorithms

\section{Considered Criteria}

System reliability, system security, total

construction cost, operation and maintenance

cost, payback period, coordination with state grid

and urban development planning, traffic

convenience, service level, the degree of damage to environment, air quality, waste discharge,

resource utilization, resource recycling

Total covered EV link flow by deploying a given number of charging facilities.

Total vehicle service distance is developed

Population density, shopping malls, roads, income rates, transportation stations, petrol stations, park areas, green areas, slope, and land values

Destruction degree on vegetation and water, waste discharge, GHG emission reduction, fine particulate matter emission reduction,

construction cost, annual operation and maintenance cost, investment pay-back period, harmonization of EVCS with the development planning of urban road network and power grid, traffic convenience, Service capability, impact on people's lives

Total profits of new charging stations

Overall equipment costs when they have met low/over load

Profit for charging station provision across a town city or region network
Chengdu City (China), electric vehicles

Nguyen-Dupuis network, electric vehicles and gasoline vehicles

Beijing (China), electric vehicles

Istambul City 3 districts (Turkey), electric vehicles

Fengtai district, Changping district, Daxing district and Chaoyang district in Beijing (China), electric vehicles

Västerås, (Sweden), electric vehicles

Ankara (Turkey), electric vehicles

Boston (USA), electric vehicles 
Table A1. Cont.

Research

Methodology

Kaya et al. [61]

Geographic information system (GIS) techniques and multicriteria decision making (MCDM) (AHP, PROMETHEE and VIKOR methods)

Kong et al. [51]

Algorithm of the three-layered optimization model

Karolemeas et al. [72]

Qualitative approach based on AHP method

Liu et al. [14]

Ma and Xie [96]

Mashhoodi and Van der Blij [62]

Pagany et al. [56]

Pal et al. [60]

Pan et al. [97]
Mixed-integer nonlinear problem (MINLP)

Mixed-integer linear problem (MILP)

Linear integer programming, Geographic information system (GIS)

Electric charging demand location (ECDL) model micro-location level using geographic information system (GIS)

Differential evolution (DE), Harris hawks optimization $(\mathrm{HHO})$ techniques, multicriteria decision-making method

Deterministic nonlinear programming, genetic algorithm (GA)

\section{Considered Criteria}

Territory, Region and Considered Vehicle Types

EV numbers, numbers of vehicle, land cost,

household income, forest, water resources,

landslide, earthquake, slope of land, air quality,

service area population, social areas, current

EVCS, patrol station, solar energy potential, substation, road, junction parking lot

Captured traffic flow by efficiently locating the FCSs, quality of service (weighted sum of the blocking probabilities), requested state of charge battery

Population density; walking distance from (1) the nearest public administration building, (2) the nearest hospital or healthcare center, (3) nearest school or university, (4) the nearest recreation and entertainment point of interest, (5) the nearest transport hub/station; density of marked or controlled parking spaces; share of households without privately parking space

Station construction cost, EV inconvenient driving cost, EV waiting cost

Daily charging operation times of EV-based dynamic ridesharing services Total cost of establishing new charging infrastructure

Walking distance calculations, including spatial neighborhood effects (e.g., the density of POIs)

Energy loss, total voltage deviation in $24 \mathrm{~h}$, number of users, land cost

Istanbul (Turkey), electric vehicles

Arizona State Highway Network (USA), electric vehicles

Greece, electric vehicles

German motorways, electric vehicles

Luxembourg, electric vehicles

Amsterdam (Nederland), electric vehicles

South-eastern Germany, electric vehicles

Hypothetic area, electric vehicles

Maintaining the existing activities of EV driver (number of missed trips, given a fixed number of public charging stations and home charging accessibility of each EV driver)
Beijing (China), electric vehicles 
Table A1. Cont.

\section{Research}

Methodology

Interviews-four main groups: professionals of

authorities, charging equipment suppliers, owners of dedicated EVCSs and professionals of public

hotspot-based EVCSs. Qualitative data were analyzed using content analysis in manual and quantitative data were analyzed using relative importance index (RII) with results obtained on a 5-point Likert scale and cost-benefit Analysis.

Sierpiński et al. [80]

Use of a travel planner to evaluate the distribution of charging stations, geographic information system (GIS) techniques

Szymańska et al. [58]

Geographic information system (GIS) techniques

Vazifeh et al. [73]

Xiao et al. [63]
Integer optimization model, geographic information system (GIS) techniques

Integer nonlinear programming, queuing theory, genetic algorithm (GA)

\section{Considered Criteria}

Territory, Region and Considered Vehicle Types

Technical feasibility, economic feasibility, lega feasibility, cultural feasibility, environmental feasibility, market feasibility

Number of travels that cannot be made (due to the lack of a charging station at a certain distance around the start point), extent of the travel caused by the need to recharge the vehicle on-route and additional energy consumption by electric vehicles required to reach the charging station

Total cost of construction, the share of high-power charging points, the availability of charging points, the coverage of densely populated and commercially developed areas with charging points and the integration with public transport Covering the entire demand region, measure of drivers' total excess driving distance to reach charging stations

Total cost of operating an EV charging station system
Public hotspots (Sri Lanka), electric vehicles

Metropolis of Upper Silesia and Dabrowa Basin (Poland), electric vehicles

Poznan (Poland), electric vehicles

City of Boston (USA), electric vehicles

The center of the Empire State Building in Manhattan Midtown, New York (USA), electric vehicles 


\section{Appendix B}

Table A2. Parameters describing draw policies-the quantities of parking lots drawn in each of the parking groups in each of the traffic analysis zone (TAZ) groups.

\begin{tabular}{|c|c|c|c|c|c|c|c|c|c|}
\hline TAZ Class & $\mathbf{A}$ & B & $\mathrm{C}$ & $\mathbf{A}$ & B & $\mathrm{C}$ & $\mathbf{A}$ & B & $\mathrm{C}$ \\
\hline Policy No. & \multicolumn{3}{|c|}{ 1-Shopping Centers ${ }^{1}$} & \multicolumn{3}{|c|}{ 2-Supermarkets } & \multicolumn{3}{|c|}{ 3-Other } \\
\hline P1 & 10 & 0 & 0 & 38 & 0 & 0 & 20 & 0 & 0 \\
\hline $\mathrm{P} 2$ & 5 & 0 & 0 & 16 & 0 & 0 & 47 & 0 & 0 \\
\hline P3 & 10 & 0 & 0 & 11 & 0 & 0 & 47 & 0 & 0 \\
\hline $\mathrm{P} 4$ & 10 & 5 & 5 & 10 & 15 & 5 & 9 & 7 & 2 \\
\hline P5 & 2 & 2 & 1 & 7 & 7 & 2 & 19 & 19 & 9 \\
\hline P6 & 7 & 5 & 2 & 3 & 3 & 1 & 19 & 19 & 9 \\
\hline P7 & 0 & 0 & 0 & 0 & 0 & 0 & 29 & 27 & 12 \\
\hline P8 & 6 & 5 & 6 & 6 & 12 & 13 & 6 & 7 & 7 \\
\hline P9 & 1 & 2 & 2 & 4 & 6 & 6 & 13 & 16 & 18 \\
\hline P10 & 3 & 5 & 6 & 2 & 3 & 2 & 13 & 16 & 18 \\
\hline P11 & 0 & 0 & 0 & 0 & 0 & 0 & 18 & 24 & 26 \\
\hline P12 & 0 & 5 & 0 & 0 & 33 & 0 & 0 & 30 & 0 \\
\hline P13 & 0 & 2 & 0 & 0 & 17 & 0 & 0 & 49 & 0 \\
\hline P14 & 0 & $\overline{5}$ & 0 & 0 & 14 & 0 & 0 & 49 & 0 \\
\hline P15 & 0 & 0 & 0 & 0 & 0 & 0 & 0 & 68 & 0 \\
\hline P16 & 0 & 0 & 6 & 0 & 0 & 21 & 0 & 0 & 41 \\
\hline P17 & 0 & 0 & 2 & 0 & 0 & 17 & 0 & 0 & 49 \\
\hline P18 & 0 & 0 & 6 & 0 & 0 & 13 & 0 & 0 & 49 \\
\hline P19 & 0 & 0 & 0 & 0 & 0 & 0 & 0 & 0 & 68 \\
\hline P20 & 10 & 5 & 6 & 15 & 7 & 1 & 15 & 7 & 2 \\
\hline P21 & 10 & 5 & 4 & 8 & 5 & 1 & 20 & 10 & 5 \\
\hline P22 & 5 & 2 & 1 & 9 & 4 & 2 & 25 & 12 & 8 \\
\hline P23 & 10 & 5 & 4 & 9 & 7 & 7 & 9 & 9 & 8 \\
\hline P24 & 10 & 5 & 6 & 20 & 9 & 4 & 8 & 5 & 1 \\
\hline P25 & 8 & 5 & 6 & 8 & 8 & 8 & 8 & 9 & 8 \\
\hline P26 & 2 & 1 & 1 & 7 & 6 & 4 & 8 & 17 & 22 \\
\hline P27 & \multicolumn{9}{|c|}{ random 68 out of 372 potential locations (no division for parking type or TAZ class) } \\
\hline
\end{tabular}

${ }^{1}$ Five potential EVCS locations assigned to "0-clean transport zones" group were selected in each policy.

Table A3. Results - median values of all the criteria computed for all the alternatives assigned to a given policy.

\begin{tabular}{|c|c|c|c|c|c|c|c|c|c|c|c|c|c|}
\hline Policy & C1.1 & C1.2 & C2.1 & C2.2 & C3.1 & C3.2 & $\mathrm{C} 4$ & C5.1 & C5.2 & C5.3 & C6 & C7 & $\mathrm{C} 8$ \\
\hline P1 & 133 & 322 & 116,446 & 192,968 & 34 & 53 & 1124 & 36.9 & 11.8 & 5.2 & 355 & 1240 & 10 \\
\hline P2 & 150 & 320 & 115,154 & 196,227 & 30 & 49 & 1088 & 39.7 & 12.4 & 5.5 & 257 & 1319 & 11 \\
\hline P3 & 153 & 324 & 113,572 & 196,086 & 30 & 49 & 1092 & 39.4 & 12.5 & 5.4 & 271.5 & 1292 & 12 \\
\hline P4 & 138 & 326 & 102,495 & 195,004 & 37 & 53 & 976 & 23.4 & 18.1 & 7.2 & 378 & 1060 & 11 \\
\hline $\mathrm{P} 4 \mathrm{x}^{1}$ & 139 & 326 & 102,415 & 195,048 & 37 & 53 & 976 & 23,4 & 18,1 & 7,2 & 378 & 1060 & 11 \\
\hline P5 & 132 & 307 & 96,560 & 193,413 & 32 & 49 & 901 & 23.0 & 18.6 & 8.3 & 241 & 1131 & 9 \\
\hline P6 & 137 & 308 & 94,103 & 191,221 & 33 & 50 & 920 & 23.2 & 18.4 & 8.1 & 296 & 1063 & 10 \\
\hline P7 & 132 & 297 & 93,603 & 189,215 & 29 & 47 & 866 & 23.5 & 19.0 & 8.8 & 160 & 1169 & 9 \\
\hline P8 & 134 & 325 & 93,747 & 192,690 & 37 & 52 & 909 & 19.0 & 17.7 & 9.6 & 359 & 1002 & 11 \\
\hline P9 & 128 & 300 & 87,005 & 187,752 & 33 & 48 & 844 & 18.1 & 17.7 & 10.8 & 230 & 1026 & 10 \\
\hline P10 & 134 & 303 & 87,826 & 189,284 & 35 & 50 & 853 & 18.5 & 18.0 & 10.4 & 274 & 966 & 10 \\
\hline P11 & 127 & 287 & 82,067 & 181,496 & 30 & 47 & 801 & 17.5 & 18.1 & 11.6 & 145 & 1025 & 9 \\
\hline P12 & 129 & 305 & 89,417 & 184,859 & 32 & 48 & 893 & 11.6 & 26.0 & 6.6 & 272 & 1115 & 9 \\
\hline P13 & 125 & 306 & 88,110 & 184,485 & 31 & 49 & 867 & 11.0 & 27.5 & 6.8 & 211 & 1148 & 8 \\
\hline P14 & 129 & 306 & 86,987 & 184,530 & 32 & 49 & 872 & 11.0 & 27.4 & 6.8 & 249 & 1111 & 8 \\
\hline P15 & 128 & 317 & 90,967 & 187,677 & 30 & 50 & 822 & 10.8 & 30.1 & 7.2 & 164 & 1172 & 7 \\
\hline P16 & 116 & 281 & 63,332 & 164,162 & 36 & 48 & 764 & 8.1 & 12.5 & 17.1 & 211 & 774 & 11 \\
\hline P17 & 114 & 268 & 57,769 & 159,358 & 34 & 46 & 746 & 7.1 & 12.0 & 17.9 & 180 & 741 & 10 \\
\hline P18 & 117 & 273 & 61,746 & 165,180 & 35 & 48 & 743 & 7.8 & 12.3 & 17.7 & 183 & 729 & 11 \\
\hline P19 & 116 & 254 & 51,030 & 155,128 & 32 & 45 & 729 & 6.2 & 11.3 & 19.5 & 109 & 639 & 10 \\
\hline P20 & 140 & 321 & 105,726 & 194,328 & 37 & 54 & 1024 & 27.6 & 16.6 & 6.6 & 377 & 1088 & 10 \\
\hline P21 & 138 & 311 & 98,878 & 191,698 & 34 & 51 & 993 & 26.5 & 16.5 & 7.0 & 337 & 1065 & 10 \\
\hline P22 & 137 & 312 & 100,581 & 194,980 & 32 & 49 & 945 & 27.5 & 16.4 & 7.9 & 265 & 1144 & 10 \\
\hline $\mathrm{P} 22 \mathrm{x}^{1}$ & 137 & 311 & 100,514 & 194,924 & 32 & 49 & 944 & 27.5 & 16.4 & 7.9 & 265 & 1145 & 10 \\
\hline $\mathrm{P} 23$ & 137 & 321 & 96,029 & 191,638 & 36 & 52 & 938 & 22.4 & 17.0 & 8.7 & 362 & 1011 & 11 \\
\hline P24 & 140 & 329 & 107,850 & 194,719 & 38 & 54 & 1022 & 26.8 & 16.5 & 6.8 & 405 & 1075 & 10 \\
\hline P25 & 136 & 321 & 95,915 & 193,003 & 37 & 52 & 925 & 21.2 & 17.4 & 9.0 & 357 & 1001 & 11 \\
\hline P26 & 127 & 301 & 86,781 & 188,738 & 32 & 48 & 832 & 17.5 & 17.7 & 11.2 & 218 & 1003 & 9 \\
\hline P27 & 127 & 301 & 86,987 & 188,561 & 32 & 49 & 832 & 17.6 & 17.7 & 11.2 & 215 & 1006 & 9 \\
\hline
\end{tabular}

\footnotetext{
${ }^{1} \mathrm{P} 4 \mathrm{x}$ and $\mathrm{P} 22 \mathrm{x}$ criteria values were obtained after generating additional alternatives for $\mathrm{P} 4$ and P22 policies.
} 
Table A4. Results— the best values of all the criteria computed for all the alternatives assigned to a given policy.

\begin{tabular}{|c|c|c|c|c|c|c|c|c|c|c|c|c|c|}
\hline Policy & C1.1 & C1.2 & C2.1 & C2.2 & C3.1 & C3.2 & C4 & C5.1 & C5.2 & C5.3 & $\mathrm{C} 6$ & C7 & $\mathrm{C} 8$ \\
\hline P1 & 158 & 350 & 126,693 & 198,545 & 40 & 59 & 1071 & 41.5 & 13.0 & 5.8 & 384 & 1385 & 13 \\
\hline P2 & 164 & 347 & 124,829 & 199,953 & 37 & 55 & 1061 & 42.3 & 13.3 & 5.9 & 314 & 1418 & 13 \\
\hline P3 & 164 & 345 & 121,999 & 199,597 & 35 & 54 & 1065 & 41.9 & 13.2 & 5.8 & 330 & 1379 & 13 \\
\hline P4 & 172 & 374 & 117,075 & 209,105 & 47 & 62 & 784 & 27.9 & 21.1 & 8.4 & 459 & 1329 & 16 \\
\hline $\mathrm{P} 4 \mathrm{x}^{1}$ & 179 & 387 & 121,564 & 211,954 & 47 & 63 & 778 & 28.7 & 21.1 & 8.7 & 460 & 1329 & 17 \\
\hline P5 & 175 & 370 & 115,889 & 210,931 & 43 & 62 & 722 & 27.9 & 22.1 & 9.8 & 346 & 1434 & 16 \\
\hline P6 & 179 & 363 & 112,866 & 209,147 & 44 & 63 & 727 & 28.3 & 21.3 & 9.7 & 366 & 1319 & 16 \\
\hline P7 & 170 & 349 & 108,753 & 206,612 & 39 & 60 & 700 & 28.0 & 22.5 & 10.6 & 210 & 1447 & 15 \\
\hline P8 & 172 & 376 & 112,951 & 207,249 & 48 & 63 & 717 & 23.8 & 20.5 & 10.9 & 446 & 1238 & 17 \\
\hline P9 & 172 & 357 & 106,873 & 208,102 & 44 & 64 & 663 & 23.4 & 20.6 & 12.5 & 329 & 1287 & 16 \\
\hline P10 & 177 & 353 & 104,467 & 206,410 & 47 & 61 & 673 & 23.1 & 21.1 & 12.2 & 359 & 1276 & 17 \\
\hline P11 & 172 & 346 & 98,903 & 203,260 & 42 & 61 & 608 & 22.8 & 21.3 & 13.3 & 214 & 1325 & 16 \\
\hline P12 & 159 & 347 & 101,807 & 200,934 & 40 & 56 & 797 & 14.0 & 29.2 & 7.5 & 313 & 1330 & 11 \\
\hline P13 & 158 & 349 & 101,280 & 203,636 & 41 & 60 & 755 & 13.7 & 31.3 & 7.9 & 286 & 1361 & 11 \\
\hline P14 & 159 & 350 & 103,462 & 204,479 & 41 & 60 & 770 & 13.9 & 30.7 & 7.9 & 294 & 1356 & 11 \\
\hline P15 & 151 & 354 & 101,910 & 201,990 & 36 & 57 & 761 & 12.7 & 32.4 & 7.9 & 187 & 1344 & 8 \\
\hline P16 & 149 & 324 & 71,922 & 181,089 & 44 & 56 & 596 & 10.0 & 14.1 & 19.0 & 225 & 918 & 14 \\
\hline P17 & 149 & 311 & 69,701 & 180,278 & 43 & 56 & 626 & 9.7 & 14.3 & 19.7 & 206 & 935 & 14 \\
\hline P18 & 151 & 317 & 71,620 & 183,321 & 44 & 58 & 623 & 10.0 & 14.3 & 19.6 & 213 & 899 & 14 \\
\hline P19 & 146 & 296 & 61,429 & 174,800 & 40 & 56 & 630 & 8.2 & 13.0 & 21.1 & 124 & 792 & 13 \\
\hline P20 & 180 & 368 & 121,914 & 208,347 & 48 & 63 & 835 & 32.6 & 19.3 & 7.9 & 458 & 1341 & 15 \\
\hline P21 & 172 & 359 & 116,124 & 206,899 & 44 & 62 & 794 & 32.2 & 19.3 & 8.3 & 435 & 1317 & 16 \\
\hline P22 & 181 & 373 & 116,226 & 211,540 & 45 & 61 & 763 & 33.0 & 19.2 & 9.4 & 373 & 1409 & 17 \\
\hline $\mathrm{P} 22 \mathrm{x}^{1}$ & 181 & 373 & 118,279 & 212,120 & 47 & 61 & 711 & 33,1 & 19,5 & 9,8 & 383 & 1444 & 17 \\
\hline P23 & 177 & 373 & 114,024 & 211,499 & 46 & 64 & 758 & 27.5 & 19.8 & 10.2 & 474 & 1263 & 17 \\
\hline P24 & 177 & 382 & 121,929 & 207,081 & 47 & 65 & 825 & 31.4 & 19.0 & 8.3 & 479 & 1308 & 15 \\
\hline P25 & 167 & 381 & 110,339 & 209,267 & 50 & 65 & 713 & 25.9 & 20.0 & 10.6 & 445 & 1251 & 17 \\
\hline P26 & 172 & 356 & 105,250 & 206,875 & 46 & 63 & 656 & 22.6 & 21.6 & 13.3 & 337 & 1292 & 17 \\
\hline P27 & 178 & 368 & 110,198 & 210,693 & 45 & 63 & 644 & 24.9 & 21.9 & 14.6 & 362 & 1297 & 17 \\
\hline
\end{tabular}

${ }^{1}$ P4x and P22x criteria values were obtained after generating additional alternatives for P4 and P22 policies.

Table A5. Results—standard deviations of criteria values computed for all the alternatives assigned to a given policy.

\begin{tabular}{|c|c|c|c|c|c|c|c|c|c|c|c|c|c|}
\hline Policy & C1.1 & C1.2 & C2.1 & C2.2 & C3.1 & C3.2 & $\mathrm{C} 4$ & C5.1 & C5.2 & C5.3 & C6 & C7 & $\mathrm{C} 8$ \\
\hline P1 & 7.4 & 8.8 & 3269 & 2057 & 1.5 & 1.7 & 19.3 & 1.3 & 0.3 & 0.2 & 9.3 & 42.4 & 1.3 \\
\hline P2 & 4.4 & 8.0 & 2671 & 1521 & 1.7 & 1.7 & 11.5 & 0.8 & 0.3 & 0.1 & 17.7 & 30.1 & 0.8 \\
\hline P3 & 3.4 & 6.3 & 2367 & 1039 & 1.4 & 1.4 & 9.6 & 0.7 & 0.2 & 0.1 & 13.9 & 24.9 & 0.5 \\
\hline $\mathrm{P} 4$ & 9.4 & 13.0 & 4445 & 4926 & 2.8 & 3.0 & 64.1 & 1.3 & 0.8 & 0.4 & 20.9 & 63.8 & 1.5 \\
\hline $\mathrm{P} 4 \mathrm{x}^{1}$ & 9.5 & 13.1 & 4452 & 4850 & 2.8 & 3.0 & 63.5 & 1.3 & 0.8 & 0.4 & 21.0 & 64.1 & 1.5 \\
\hline P5 & 11.9 & 16.1 & 5281 & 6109 & 3.4 & 3.6 & 65.0 & 1.5 & 0.9 & 0.4 & 28.6 & 77.3 & 1.8 \\
\hline P6 & 11.4 & 15.4 & 5183 & 6409 & 3.1 & 3.3 & 66.1 & 1.5 & 0.9 & 0.4 & 20.7 & 74.0 & $\begin{array}{l}1.0 \\
1.7\end{array}$ \\
\hline P7 & 11.1 & 15.1 & 4797 & 6677 & 2.9 & 3.2 & 61.0 & 1.3 & 0.8 & 0.4 & 15.5 & 74.5 & 1.5 \\
\hline P8 & 9.9 & 13.8 & 4418 & 5147 & 2.9 & 3.1 & 59.3 & 1.3 & 0.8 & 0.4 & 22.2 & 64.0 & 1.6 \\
\hline P9 & 12.6 & 16.8 & 5106 & 6842 & 3.4 & 3.7 & 64.1 & 1.4 & 0.9 & 0.5 & 27.9 & 75.9 & 1.9 \\
\hline P10 & 11.4 & 15.6 & 4910 & 6341 & 3.1 & 3.4 & 63.1 & 1.4 & 0.9 & 0.5 & 19.4 & 73.4 & 1.8 \\
\hline P11 & 12.2 & 16.7 & 5110 & 7991 & 3.2 & 3.5 & 59.9 & 1.4 & 0.9 & 0.5 & 15.5 & 77.1 & 1.8 \\
\hline P12 & 8.3 & 11.7 & 3252 & 5163 & 2.1 & 2.3 & 40.8 & 0.6 & 0.9 & 0.2 & 11.8 & 57.5 & 0.8 \\
\hline P13 & 10.5 & 13.6 & 3929 & 6888 & 2.7 & 2.9 & 51.5 & 0.8 & 0.9 & 0.3 & 22.6 & 65.0 & 1.2 \\
\hline P14 & 10.1 & 13.4 & 3820 & 6156 & 2.6 & 2.8 & 54.5 & 0.8 & 1.0 & 0.3 & 14.2 & 67.6 & 1.2 \\
\hline P15 & 8.3 & 10.7 & 3284 & 5916 & 1.9 & 2.1 & 40.9 & 0.6 & 0.7 & 0.2 & 10.7 & 53.9 & 0.7 \\
\hline P16 & 9.3 & 11.2 & 2674 & 5170 & 2.4 & 2.6 & 54.0 & 0.5 & 0.5 & 0.5 & 3.8 & 41.2 & 1.2 \\
\hline P17 & 10.6 & 12.9 & 3444 & 6355 & 2.7 & 2.8 & 51.6 & 0.6 & 0.5 & 0.5 & 10.6 & $\begin{array}{l}41.2 \\
47.3\end{array}$ & $\begin{array}{l}1.2 \\
1.5\end{array}$ \\
\hline P18 & 11.1 & 13.1 & 3225 & 5692 & 2.7 & 2.9 & 52.8 & 0.7 & 0.5 & 0.6 & 12.0 & 48.8 & 1.6 \\
\hline P19 & 10.6 & 13.2 & 2905 & 6367 & 2.5 & 2.7 & 42.4 & 0.6 & 0.5 & 0.5 & 4.9 & 43.8 & 1.7 \\
\hline P20 & 9.3 & 12.9 & 4513 & 4543 & 2.7 & 2.9 & 62.0 & 1.5 & 0.7 & 0.3 & 20.6 & 64.7 & 1.4 \\
\hline P21 & 10.3 & 14.6 & 5231 & 5884 & 3.1 & 3.3 & 66.3 & 1.5 & 0.8 & 0.4 & 20.9 & 68.8 & 1.6 \\
\hline P22 & 11.7 & 15.1 & 4923 & 5434 & 3.2 & 3.4 & 63.9 & 1.5 & 0.8 & 0.4 & 28.9 & 73.1 & 1.8 \\
\hline $\mathrm{P}_{22 \mathrm{x}^{1}}$ & 11.6 & 15.3 & 4973 & 5502 & 3.2 & 3.4 & 63.2 & 1.5 & 0.8 & 0.4 & 29.0 & 73.0 & 1.7 \\
\hline P23 & 10.7 & 14.2 & 4751 & 5568 & 3.0 & 3.2 & 66.9 & 1.3 & 0.8 & 0.4 & 22.0 & 67.2 & 1.6 \\
\hline P24 & 8.8 & 12.3 & 4194 & 4216 & 2.7 & 2.9 & 62.7 & 1.3 & 0.7 & 0.3 & 21.0 & 59.8 & 1.4 \\
\hline P25 & 10.3 & 14.2 & 4513 & 5256 & 3.0 & 3.2 & 65.1 & 1.3 & 0.8 & 0.4 & 22.8 & 67.9 & 1.6 \\
\hline P26 & 12.9 & 16.9 & 5126 & 6844 & 3.5 & 3.8 & 62.2 & 1.3 & 0.9 & 0.5 & 26.6 & 75.1 & 1.8 \\
\hline P27 & 13.1 & 17.1 & 5915 & 7140 & 3.5 & 3.7 & 63.6 & 2.0 & 1.2 & 0.8 & 30.0 & 82.7 & $\begin{array}{l}1.0 \\
1.9\end{array}$ \\
\hline
\end{tabular}

\footnotetext{
${ }^{1} \mathrm{P} 4 \mathrm{x}$ and P22x criteria values were obtained after generating additional alternatives for P4 and P22 policies.
} 


\section{References}

1. Knobloch, F.; Hanssen, S.V.; Lam, A.; Pollitt, H.; Salas, P.; Chewpreecha, U.; Huijbregts, M.A.J.; Mercure, J.-F. Net Emission Reductions from Electric Cars and Heat Pumps in 59 World Regions over Time. Nat. Sustain. 2020, 3, 437-447. [CrossRef] [PubMed]

2. Del Pero, F.; Delogu, M.; Pierini, M. Life Cycle Assessment in the Automotive Sector: A Comparative Case Study of Internal Combustion Engine (ICE) and Electric Car. Procedia Struct. Integr. 2018, 12, 521-537. [CrossRef]

3. Mathieu, L.; Poliscanova, J.; Carlos Calvo, A.; Muzi, N.; Mathieu, L.; Todts, W. EU Public Charging Infrastructure Needs until 2030; European Federation for Transport and Environment AISBL: Brussels, Belgium, 2020.

4. Yong, T.; Park, C. A Qualitative Comparative Analysis on Factors Affecting the Deployment of Electric Vehicles. Energy Procedia 2017, 128, 497-503. [CrossRef]

5. Adhikari, M.; Ghimire, L.P.; Kim, Y.; Aryal, P.; Khadka, S.B. Identification and Analysis of Barriers against Electric Vehicle Use. Sustainability 2020, 12, 4850. [CrossRef]

6. Vovk, Y. Resource-Efficient Intelligent Transportation Systems as a Basis for Sustainable Development. Overview of Initiatives and Strategies. J. Sustain. Dev. Transp. Logist. 2016, 1, 6-10. [CrossRef]

7. Kaiser, R.; Graver, C. Analysis of the Infrastructure for Recharging Electric Vehicles; SAE Technical Paper No. 800112; SAE: Evanston, IL, USA, 1980. [CrossRef]

8. Noel, L.; Zarazua de Rubens, G.; Sovacool, B.K.; Kester, J. Fear and Loathing of Electric Vehicles: The Reactionary Rhetoric of Range Anxiety. Energy Res. Soc. Sci. 2019, 48, 96-107. [CrossRef]

9. Gnann, T.; Plötz, P.; Wietschel, M. How to Address the Chicken-Egg-Problem of Electric Vehicles? Introducing an Interaction Market Diffusion Model for EVs and Charging Infrastructure. In Proceedings of the ECEEE 2015 Summer Study on Energy Efficiency: First Fuel Now, ECEEE, Toulon/Hyères, France, 1-6 June 2015; pp. 873-884.

10. Harrison, G.; Thiel, C. An Exploratory Policy Analysis of Electric Vehicle Sales Competition and Sensitivity to Infrastructure in Europe. Technol. Forecast. Soc. Chang. 2017, 114, 165-178. [CrossRef]

11. Baresch, M.; Moser, S. Allocation of E-Car Charging: Assessing the Utilization of Charging Infrastructures by Location. Transp. Res. A Policy Pract. 2019, 124, 388-395. [CrossRef]

12. Kizhakkan, A.R.; Rathore, A.K.; Awasthi, A. Review of Electric Vehicle Charging Station Location Planning. In Proceedings of the 2019 IEEE Transportation Electrification Conference (ITEC-India), Bengaluru, India, 17-19 December 2019.

13. Pagany, R.; Ramirez Camargo, L.; Dorner, W. A Review of Spatial Localization Methodologies for the Electric Vehicle Charging Infrastructure. Int. J. Sustain. Transp. 2019, 13, 433-449. [CrossRef]

14. Liu, J.; Peper, J.; Lin, G.; Zhou, Y.; Awasthi, S.; Li, Y.; Rehtanz, C. A Planning Strategy Considering Multiple Factors for Electric Vehicle Charging Stations along German Motorways. Int. J. Electr. Power Energy Syst. 2021, 124, 106379. [CrossRef]

15. Zhang, Y.; Liu, X.; Zhang, T.; Gu, Z. Review of the Electric Vehicle Charging Station Location Problem. In Dependability in Sensor, Cloud, and Big Data Systems and Applications; Communications in Computer and Information Science; Wang, G., Bhuiyan, M.Z.A., De Capitani di Vimercati, S., Ren, Y., Eds.; Springer: Singapore, 2019; Volume 1123, pp. 435-445. ISBN 9789811513039.

16. Zhang, Q.; Li, H.; Zhu, L.; Campana, P.E.; Lu, H.; Wallin, F.; Sun, Q. Factors Influencing the Economics of Public Charging Infrastructures for EV-A Review. Renew. Sustain. Energy Rev. 2018, 94, 500-509. [CrossRef]

17. Hsu, C.-W.; Fingerman, K. Public Electric Vehicle Charger Access Disparities across Race and Income in California. Transp. Policy 2021, 100, 59-67. [CrossRef]

18. Dixon, J.; Bell, K. Electric Vehicles: Battery Capacity, Charger Power, Access to Charging and the Impacts on Distribution Networks. eTransportation 2020, 4, 100059. [CrossRef]

19. Moghaddam, V.; Ahmad, I.; Habib, D.; Masoumc, M.A.S. Dispatch Management of Portable Charging Stations in Electric Vehicle Networks. eTransportation 2021, 8, 100112. [CrossRef]

20. Bayram, I.S.; Bayhan, S. Location Analysis of Electric Vehicle Charging Stations for Maximum Capacity and Coverage. In Proceedings of the 2020 IEEE 14th International Conference on Compatibility, Power Electronics and Power Engineering (CPE-POWERENG), Setubal, Portugal, 8-10 July 2020; pp. 409-414.

21. Islam, M. A Review of Techniques for Optimal Placement and Sizing of Electric Vehicle Charging Stations. Electrotech. Rev. 2015, 1, 124-128. [CrossRef]

22. Ahmadian, A.; Mohammadi-Ivatloo, B.; Elkamel, A. A Review on Plug-in Electric Vehicles: Introduction, Current Status, and Load Modeling Techniques. J. Modern Power Syst. Clean Energy 2020, 8, 412-425. [CrossRef]

23. Qiu, Y.; Du, Y.; Yu, S.; Jiang, S. Location Design of Electrification Road in Transportation Networks for On-Way Charging. J. Adv. Transp. 2020, 2020, 1-13. [CrossRef]

24. Akbari, M.; Brenna, M.; Longo, M. Optimal Locating of Electric Vehicle Charging Stations by Application of Genetic Algorithm. Sustainability 2018, 10, 1076. [CrossRef]

25. Yao, L.; Damiran, Z.; Lim, W.H. Optimal Charging and Discharging Scheduling for Electric Vehicles in a Parking Station with Photovoltaic System and Energy Storage System. Energies 2017, 10, 550. [CrossRef]

26. Chrysanidis, G.; Kosmanos, D.; Argyriou, A.; Maglaras, L. Stochastic Optimization of Electric Vehicle Charging Stations. In Proceedings of the 2019 IEEE SmartWorld, Ubiquitous Intelligence \& Computing, Advanced \& Trusted Computing, Scalable Computing \& Communications, Cloud \& Big Data Computing, Internet of People and Smart City Innovation (SmartWorld/SCALCOM/UIC/ATC/CBDCom/IOP/SCI), Leicester, UK, 19-23 August 2019; pp. 1-7. 
27. Ching, T.W. Electric Vehicle Charging Stations in Macau. WEVJ 2010, 4, 677-682. [CrossRef]

28. Soares, F.J.; Barbeiro, P.N.P.; Gouveia, C.; Lopes, J.A.P. Impacts of Plug-in Electric Vehicles Integration in Distribution Networks Under Different Charging Strategies. In Plug in Electric Vehicles in Smart Grids; Power Systems; Rajakaruna, S., Shahnia, F., Ghosh, A., Eds.; Springer: Singapore, 2015; pp. 89-137. ISBN 978-981-287-316-3.

29. Guttenberg, M.; Sripad, S.; Bills, A.; Viswanathan, V. INCEPTS: Software for High-Fidelity Electric Vehicle En Route State of Charge Estimation, Fleet Analysis and Charger Deployment. eTransportation 2021, 7, 100106. [CrossRef]

30. Daina, N.; Sivakumar, A.; Polak, J.W. Modelling Electric Vehicles Use: A Survey on the Methods. Renew. Sustain. Energy Rev. 2017, 68, 447-460. [CrossRef]

31. Pareschi, G.; Küng, L.; Georges, G.; Boulouchos, K. Are Travel Surveys a Good Basis for EV Models? Validation of Simulated Charging Profiles against Empirical Data. Appl. Energy 2020, 275, 115318. [CrossRef]

32. Helmus, J.R.; Lees, M.H.; van den Hoed, R. A Data Driven Typology of Electric Vehicle User Types and Charging Sessions. Transp. Res. Part C Emeg. Technol. 2020, 115, 102637. [CrossRef]

33. Kavianipour, M.; Fakhrmoosavi, F.; Singh, H.; Ghamami, M.; Zockaie, A.; Ouyang, Y.; Jackson, R. Electric Vehicle Fast Charging Infrastructure Planning in Urban Networks Considering Daily Travel and Charging Behavior. Transp. Res. Part D Transp. Environ. 2021, 93, 102769. [CrossRef]

34. Bessler, S.; Grønbæk, J. Routing EV Users Towards an Optimal Charging Plan. WEVJ 2012, 5, 688-695. [CrossRef]

35. Florio, A.M.; Absi, N.; Feillet, D. Routing Electric Vehicles on Congested Street Networks. Transp. Sci. 2021, 55, 238-256. [CrossRef]

36. Bouguerra, S.; Bhar Layeb, S. Determining Optimal Deployment of Electric Vehicles Charging Stations: Case of Tunis City, Tunisia. Case Stud. Tansp. Policy 2019, 7, 628-642. [CrossRef]

37. Efthymiou, D.; Chrysostomou, K.; Morfoulaki, M.; Aifantopoulou, G. Electric Vehicles Charging Infrastructure Location: A Genetic Algorithm Approach. Eur. Transp. Res. Rev. 2017, 9, 27. [CrossRef]

38. Jochem, P.; Szimba, E.; Reuter-Oppermann, M. How Many Fast-Charging Stations Do We Need along European Highways? Transp. Res. Part D Transp. Environ. 2019, 73, 120-129. [CrossRef]

39. Gong, D.; Tang, M.; Buchmeister, B.; Zhang, H. Solving Location Problem for Electric Vehicle Charging Stations-A Sharing Charging Model. IEEE Access 2019, 7, 138391-138402. [CrossRef]

40. Guler, D.; Yomralioglu, T. Suitable Location Selection for the Electric Vehicle Fast Charging Station with AHP and Fuzzy AHP Methods Using GIS. Ann. GIS 2020, 26, 169-189. [CrossRef]

41. Bian, C.; Li, H.; Wallin, F.; Avelin, A.; Lin, L.; Yu, Z. Finding the Optimal Location for Public Charging Stations-A GIS-Based MILP Approach. Energy Procedia 2019, 158, 6582-6588. [CrossRef]

42. Lin, H.; Bian, C.; Li, H.; Sun, Q.; Wennersten, R. Optimal Siting and Sizing of Public Charging Stations in Urban Area. DESTech Trans. Environ. Energy Earth Sci. 2019. [CrossRef]

43. Rathnayake, R.M.D.I.M.; Jayawickrama, T.S.; Melagoda, D.G. The Feasibility of Establishing Electric Vehicle Charging Stations at Public Hotspots in Sri Lanka. In Proceedings of the 2019 Moratuwa Engineering Research Conference (MERCon), Moratuwa, Sri Lanka, 3-5 July 2019; pp. 510-514.

44. Rosato, A.; Sibilio, S.; Ciampi, G.; Entchev, E.; Ribberink, H. Energy, Environmental and Economic Effects of Electric Vehicle Charging on the Performance of a Residential Building-Integrated Micro-Trigeneration System. Energy Procedia 2017, 111, 699-709. [CrossRef]

45. Arcos-Vargas, A.; Hidalgo, A. Economic Analysis of Recharging Electric Vehicles. In The Role of the Electric Vehicle in the Energy Transition; Green Energy and Technology; Arcos-Vargas, A., Ed.; Springer International Publishing: Cham, Switzerland, 2021; pp. 81-92. ISBN 978-3-030-50632-2.

46. Harighi, T.; Padmanaban, S.; Bayindir, R.; Hossain, E.; Holm-Nielsen, J.B. Electric Vehicle Charge Stations Location Analysis and Determination-Ankara (Turkey) Case Study. Energies 2019, 12, 3472. [CrossRef]

47. Almaghrebi, A.; Aljuheshi, F.; Rafaie, M.; James, K.; Alahmad, M. Data-Driven Charging Demand Prediction at Public Charging Stations Using Supervised Machine Learning Regression Methods. Energies 2020, 13, 4231. [CrossRef]

48. Wang, H.; Zhao, D.; Meng, Q.; Ong, G.P.; Lee, D.-H. A Four-Step Method for Electric-Vehicle Charging Facility Deployment in a Dense City: An Empirical Study in Singapore. Transp. Res. A Policy Pract. 2019, 119, 224-237. [CrossRef]

49. Figenbaum, E. Can Battery Electric Light Commercial Vehicles Work for Craftsmen and Service Enterprises? Energy Policy 2018, 120, 58-72. [CrossRef]

50. Aljohani, K.; Thompson, R.G. Last Mile Delivery Activities in the City Centre-Insights into Current Practices and Characteristics of Delivery Trips. Transp. Res. Procedia 2020, 46, 261-268. [CrossRef]

51. Kong, C.; Jovanovic, R.; Bayram, I.; Devetsikiotis, M. A Hierarchical Optimization Model for a Network of Electric Vehicle Charging Stations. Energies 2017, 10, 675. [CrossRef]

52. Arslan, O.; Karaşan, O.E. A Benders Decomposition Approach for the Charging Station Location Problem with Plug-in Hybrid Electric Vehicles. Transp. Res. Part B Methodol. 2016, 93, 670-695. [CrossRef]

53. Giménez-Gaydou, D.A.; Ribeiro, A.S.N.; Gutiérrez, J.; Antunes, A.P. Optimal Location of Battery Electric Vehicle Charging Stations in Urban Areas: A New Approach. Int. J. Sustain. Transp. 2016, 10, 393-405. [CrossRef]

54. Csiszár, C. Demand Calculation Method for Electric Vehicle Charging Station Locating and Deployment. Period. Polytech. Civil Eng. 2019, 63, 255-265. [CrossRef] 
55. Csiszár, C.; Csonka, B.; Földes, D.; Wirth, E.; Lovas, T. Urban Public Charging Station Locating Method for Electric Vehicles Based on Land Use Approach. J. Transp. Geogr. 2019, 74, 173-180. [CrossRef]

56. Pagany, R.; Marquardt, A.; Zink, R. Electric Charging Demand Location Model-A User- and Destination-Based Locating Approach for Electric Vehicle Charging Stations. Sustainability 2019, 11, 2301. [CrossRef]

57. Adacher, L. Heuristics for Electric Vehicle Charging Station Allocation Problem. In Proceedings of the 2018 5th International Conference on Mathematics and Computers in Sciences and Industry (MCSI), Confu, Greece, 25-27 August 2018; pp. 72-76.

58. Szymańska, P.; Szczur, A.; Zmuda-Trzebiatowski, P. Criteria for the Appraisal of the Location of Electric Vehicle Charging Stations. Case Study: Network of Charging Stations in Poznan. Prace Kom. Geogr. Komun. PTG 2019, 22, 20-33. [CrossRef]

59. Huang, Y.; Kockelman, K.M. Electric Vehicle Charging Station Locations: Elastic Demand, Station Congestion, and Network Equilibrium. Transp. Res. Part D Transp. Environ. 2020, 78, 102179. [CrossRef]

60. Pal, A.; Bhattacharya, A.; Chakraborty, A.K. Allocation of Electric Vehicle Charging Station Considering Uncertainties. Sustain. Energy Grids Netw. 2021, 25, 100422. [CrossRef]

61. Kaya, Ö.; Tortum, A.; Alemdar, K.D.; Çodur, M.Y. Site Selection for EVCS in Istanbul by GIS and Multi-Criteria Decision-Making. Transp. Res. Part D Transp. Environ. 2020, 80, 102271. [CrossRef]

62. Mashhoodi, B.; van der Blij, N. Drivers' Range Anxiety and Cost of New EV Chargers in Amsterdam: A Scenario-Based Optimization Approach. Ann. GIS 2020, 1-12. [CrossRef]

63. Xiao, D.; An, S.; Cai, H.; Wang, J.; Cai, H. An Optimization Model for Electric Vehicle Charging Infrastructure Planning Considering Queuing Behavior with Finite Queue Length. J. Energy Storage 2020, 29, 101317. [CrossRef]

64. Bai, X.; Chin, K.-S.; Zhou, Z. A Bi-Objective Model for Location Planning of Electric Vehicle Charging Stations with GPS Trajectory Data. Comput. Ind. Eng. 2019, 128, 591-604. [CrossRef]

65. Feng, J.; Xu, S.X.; Li, M. A Novel Multi-Criteria Decision-Making Method for Selecting the Site of an Electric-Vehicle Charging Station from a Sustainable Perspective. Sustain. Cities Soc. 2021, 65, 102623. [CrossRef]

66. Li, K.; Wang, S. Electric Vehicle Charging Station Deployment for Minimizing Construction Cost. In Big Data Analytics and Knowledge Discovery; Lecture Notes in Computer Science; Bellatreche, L., Chakravarthy, S., Eds.; Springer International Publishing: Cham, Switzerland, 2017; Volume 10440, pp. 471-485. ISBN 978-3-319-64282-6.

67. Ji, D.; Zhao, Y.; Dong, X.; Zhao, M.; Yang, L.; Lv, M.; Chen, G. A Spatial-Temporal Model for Locating Electric Vehicle Charging Stations. In Embedded Systems Technology; Communications in Computer and Information Science; Bi, Y., Chen, G., Deng, Q., Wang, Y., Eds.; Springer: Singapore, 2018; Volume 857, pp. 89-102. ISBN 9789811310256.

68. Wang, M.; Liu, K. Optimization of Electric Vehicle Charging Station Location Based on Game Theory. In Proceedings of the Proceedings 2011 International Conference on Transportation, Mechanical, and Electrical Engineering (TMEE), Changchun, China, 16-18 December 2011; pp. 809-812.

69. Guo, S.; Zhao, H. Optimal Site Selection of Electric Vehicle Charging Station by Using Fuzzy TOPSIS Based on Sustainability Perspective. Appl. Energy 2015, 158, 390-402. [CrossRef]

70. Erbaş, M.; Kabak, M.; Özceylan, E.; Çetinkaya, C. Optimal Siting of Electric Vehicle Charging Stations: A GIS-Based Fuzzy Multi-Criteria Decision Analysis. Energy 2018, 163, 1017-1031. [CrossRef]

71. Staniek, M.; Sierpiński, G. Charging Station Distribution Model-The Concept of Using the Locations of Petrol Stations in the City. In Modern Traffic Engineering in the System Approach to the Development of Traffic Networks; Advances in Intelligent Systems and Computing; Macioszek, E., Sierpiński, G., Eds.; Springer International Publishing: Cham, Switzerland, 2020; Volume 1083, pp. 99-113. ISBN 978-3-030-34068-1.

72. Karolemeas, C.; Tsigdinos, S.; Tzouras, P.G.; Nikitas, A.; Bakogiannis, E. Determining Electric Vehicle Charging Station Location Suitability: A Qualitative Study of Greek Stakeholders Employing Thematic Analysis and Analytical Hierarchy Process. Sustainability 2021, 13, 2298. [CrossRef]

73. Vazifeh, M.M.; Zhang, H.; Santi, P.; Ratti, C. Optimizing the Deployment of Electric Vehicle Charging Stations Using Pervasive Mobility Data. Transp. Res. A Policy Pract. 2019, 121, 75-91. [CrossRef]

74. Chraibi, K.; Chraibi, A.; Chaker, I.; Zahi, A.; Bekrar, A. Hybrid Metaheuristic to Solve Location Problem for Electric Vehicles Charging Stations. In Proceedings of the 2018 IEEE International Conference on Technology Management, Operations and Decisions (ICTMOD), Marrakech, Morocco, 21-23 November 2018; pp. 12-17.

75. Gao, H.; Liu, K.; Peng, X.; Li, C. Optimal Location of Fast Charging Stations for Mixed Traffic of Electric Vehicles and Gasoline Vehicles Subject to Elastic Demands. Energies 2020, 13, 1964. [CrossRef]

76. Catalbas, M.C.; Yildirim, M.; Gulten, A.; Kurum, H. Estimation of Optimal Locations for Electric Vehicle Charging Stations. In Proceedings of the 2017 IEEE International Conference on Environment and Electrical Engineering and 2017 IEEE Industrial and Commercial Power Systems Europe (EEEIC/I\&CPS Europe), Milano, Italy, 6-9 June 2017; pp. 1-4.

77. Lee, C.; Han, J. Benders-and-Price Approach for Electric Vehicle Charging Station Location Problem under Probabilistic Travel Range. Transp. Res. Part B Methodol. 2017, 106, 130-152. [CrossRef]

78. Anjos, M.F.; Gendron, B.; Joyce-Moniz, M. Increasing Electric Vehicle Adoption through the Optimal Deployment of Fast-Charging Stations for Local and Long-Distance Travel. Eur. J. Oper. Res. 2020, 285, 263-278. [CrossRef]

79. Babu, P.V.; Swarnasri, K. Multi-Objective Optimal Allocation of Electric Vehicle Charging Stations in Radial Distribution System Using Teaching Learning Based Optimization. Int. J. Renew. Energy Res. 2020, 10, 366-377. 
80. Sierpiński, G.; Staniek, M.; Kłos, M.J. Decision Making Support for Local Authorities Choosing the Method for Siting of In-City EV Charging Stations. Energies 2020, 13, 4682. [CrossRef]

81. Zhang, M. Location Planning of Electric Vehicle Charging Station. IOP Conf. Ser. Mater. Sci. Eng. 2018, 394, 042126. [CrossRef]

82. Machelski, A.; Grzeczka, B. Multi-Criteria Analysis of the Division of the Poznan City into Areas with Locations Designated for Installation and Operation of Electric Vehicle Charging Stations. Transp. Miej. Reg. 2020, 8, 20-24.

83. Bonges, H.A.; Lusk, A.C. Addressing Electric Vehicle (EV) Sales and Range Anxiety through Parking Layout, Policy and Regulation. Transp. Res. A Policy Pract. 2016, 83, 63-73. [CrossRef]

84. Yang, Y.; Diez-Roux, A.V. Walking Distance by Trip Purpose and Population Subgroups. Am. J. Prev. Med. 2012, 43, 11-19. [CrossRef]

85. Millward, H.; Spinney, J.; Scott, D. Active-Transport Walking Behavior: Destinations, Durations, Distances. J. Transp. Geogr. 2013, 28, 101-110. [CrossRef]

86. Gunn, L.D.; King, T.L.; Mavoa, S.; Lamb, K.E.; Giles-Corti, B.; Kavanagh, A. Identifying Destination Distances That Support Walking Trips in Local Neighborhoods. J. Transp. Health 2017, 5, 133-141. [CrossRef]

87. Guitouni, A.; Martel, J.-M. Tentative Guidelines to Help Choosing an Appropriate MCDA Method. Eur. J. Oper. Res. 1998, 109, 501-521. [CrossRef]

88. Roy, B.; Słowiński, R. Questions Guiding the Choice of a Multicriteria Decision Aiding Method. EURO J. Decis. Process. 2013, 1, 69-97. [CrossRef]

89. Sawicka, H. Metoda Reorganizacji Systemu Dystrybucji Towarów; Politechnika Warszawska: Warsaw, Poland, 2012.

90. Sawicka, H. The Methodology of Solving Stochastic Multiple Criteria Ranking Problems Applied in Transportation. Transp. Res. Procedia 2020, 47, 219-226. [CrossRef]

91. Jaszkiewicz, A.; Słowiński, R. The Light Beam Search-Outranking Based Interactive Procedure for Multiple-Objective Mathematical Programming. In Advances in Multicriteria Analysis; Nonconvex Optimization and Its Applications; Springer: Boston, MA, USA, 1995; Volume 5, pp. 129-146. ISBN 978-1-4757-2383-0.

92. Jaszkiewicz, A.; Słowiński, R. The 'Light Beam Search' Approach-An Overview of Methodology Applications. Eur. J. Oper. Res. 1999, 113, 300-314. [CrossRef]

93. Miettinen, K. Nonlinear Multiobjective Optimization; International Series in Operations Research \& Management Science; Kluwer Academic Publishers: Boston, MA, USA, 1999; ISBN 978-0-7923-8278-2.

94. Ratajczak, A.; Zmuda-Trzebiatowski, P. Evaluation of Walking and Cycling Trip Planners in the Poznan Agglomeration. Prace Naukowe Politech. Warsz. Transp. 2017, 117, 293-302.

95. Ratajczak, A.; Zmuda-Trzebiatowski, P.; Walerjańczyk, W. Functional Evaluation of Bicycle Trip Planners in the Poznań Agglomeration. Transp. Miej. Reg. 2018, 3, 27-32.

96. Ma, T.-Y.; Xie, S. Optimal Fast Charging Station Locations for Electric Ridesharing with Vehicle-Charging Station Assignment. Transp. Res. Part D Transp. Environ. 2021, 90, 102682. [CrossRef]

97. Pan, L.; Yao, E.; Yang, Y.; Zhang, R. A Location Model for Electric Vehicle (EV) Public Charging Stations Based on Drivers' Existing Activities. Sustain. Cities Soc. 2020, 59, 102192. [CrossRef] 